IZA DP No. 4922

The Development of Multidimensional Poverty in Germany 1985-2007

Christopher Busch

Andreas Peichl

May 2010 


\title{
The Development of Multidimensional Poverty in Germany 1985-2007
}

\author{
Christopher Busch \\ University of Cologne \\ Andreas Peichl \\ IZA, University of Cologne, ISER and CESifo
}

Discussion Paper No. 4922

May 2010

IZA

P.O. Box 7240

53072 Bonn

Germany

Phone: +49-228-3894-0

Fax: +49-228-3894-180

E-mail: iza@iza.org

Any opinions expressed here are those of the author(s) and not those of IZA. Research published in this series may include views on policy, but the institute itself takes no institutional policy positions.

The Institute for the Study of Labor (IZA) in Bonn is a local and virtual international research center and a place of communication between science, politics and business. IZA is an independent nonprofit organization supported by Deutsche Post Foundation. The center is associated with the University of Bonn and offers a stimulating research environment through its international network, workshops and conferences, data service, project support, research visits and doctoral program. IZA engages in (i) original and internationally competitive research in all fields of labor economics, (ii) development of policy concepts, and (iii) dissemination of research results and concepts to the interested public.

IZA Discussion Papers often represent preliminary work and are circulated to encourage discussion. Citation of such a paper should account for its provisional character. A revised version may be available directly from the author. 
IZA Discussion Paper No. 4922

May 2010

\section{ABSTRACT \\ The Development of Multidimensional Poverty in Germany 1985-2007}

This paper deals with concepts of multidimensional poverty measurement and applies them to Germany. Three concepts of poverty are examined and included into one multidimensional approach: economic well being, capability and social exclusion. The empirical application relies on indices introduced by Bourguigon and Chakravarty (2003), and Alkire and Foster (2008). It uses data from the German Socio-Economic Panel study. The indices are tested for their robustness in several aspects, and the influence of changing levels of substitutability between achievements on the poverty dimensions is examined. It transpires that the depth of poverty is relatively stable for the period 1985 to 2007 . A structural analysis of the poor in 2007 reveals that the group at greatest risk of poverty is the unemployed.

JEL Classification: $\quad$ 100, 132, O15, D63

Keywords: multidimensional measurement, poverty, deprivation, inequality

Corresponding author:

Andreas Peichl

IZA

P.O. Box 7240

53072 Bonn

Germany

E-Mail: peichl@iza.org 


\section{Introduction}

Poverty in terms of income has been continually rising in Germany for the past 20 years, as, for example, the German Federal Government's 3rd Report on Poverty and Wealth shows (BMAS, 2008, pp. 25-26). Following the idea that poverty is a phenomenon that cannot be fully captured by income, the report speaks of a "risk of poverty" due to low income rather than of "poverty" itself. Poverty is generally understood as a lack of well-being or welfare (Strengmann-Kuhn, 2004, p. 3). Using a lack of income as an indicator for poverty assumes income to be a good proxy for welfare. According to standard economic theory, income provides no direct utility to households. The assumption behind purely income-based poverty measures is that goods and services (and thus welfare) can be purchased via markets. This directly leads to the problem of the income approach: markets do not exist for every product or service, for example public goods, and in some settings markets work imperfectly (Thorbecke, 2005, p. 5). A possible solution, returning to the concept of relative deprivation as introduced by Townsend (1974), is to measure welfare more directly, instead of using income as a proxy for it. For example, Deutsch and Silber (2005) suggest measuring the household's access to durable goods. Waglé (2008a, p. 560) points out that "poverty is increasingly conceived as a latent concept that has never been defined precisely neither has there been a single, commonly agreeable proxy indicator to gauge it". As a consequence, more attributes than income need to be taken into account.

This paper deals with several concepts of multidimensional poverty measurement and then applies them to Germany. Three concepts of poverty are considered and, following Waglé (2008b), included into one multidimensional approach: economic well-being, capability and social exclusion. The empirical application relies on a methodology introduced by Bourguignon and Chakravarty (2003), and Alkire and Foster (2008). The aim is to not only identify the poor via this multidimensional concept but also to aggregate given information into indices that should reveal further insights into the depth, strength and severity of poverty. These indices are tested for their robustness in several aspects, and the influence of changing levels of substitution between achievements in the poverty dimensions is examined. The empirical application uses data from the German Socio-Economic Panel study.

Our analysis shows that the level of substitution between achievements in the poverty dimensions has almost no influence on the poverty index. Overall, there is no stable trend in the poverty rate. Furthermore, depth of poverty is relatively stable for the observed period. An EastWest comparison finds that there is a trend towards less inequality among the poor in (the for- 
mer) West Germany. A structural analysis of the poor in 2007 reveals that it is the unemployed who face the greatest risk of poverty.

The following section introduces some theory behind the topic and the motivation for the choice of poverty dimensions for the empirical application. Section 3 presents a short overview of existing empirical work on multidimensional poverty measurement in Germany. Section 4 introduces the methodology of multidimensional poverty assessment and explains the indices used. The empirical results for Germany are presented in section 5. In part one and two of this analysis, two attributes of poverty are considered, and the focus lies on technical aspects of the indices, especially the influence of substitutability. In section 5.3, a further attribute is taken into account and the development of poverty is analyzed in greater detail. Section 5.4 changes the focus towards the situation of those who are poor. The development of inequality among the poor is analyzed and compared for East and West Germany. The section closes with a structural analysis of the poor. Section 6 concludes.

\section{Multiple dimensions of poverty: Theoretical aspects}

A possible starting point for the assessment of poverty is the concept of relative deprivation which originates from Townsend (1974). In short, the approach focuses on the standard of living measured by the access of individuals to resources commonly regarded as necessary. It aims at a more direct measurement of economic well-being than a pure income approach.

A theoretical concept which goes beyond the understanding of poverty as a lack of economic well-being is the capability approach introduced by Armatya Sen. According to this approach, the "quality of life [has] to be assessed in terms of the capability to achieve valuable functionings" (Sen, 1993, p.31). Spoken in terms of poverty, the "denial of opportunities of living a tolerable life" (Anand and Sen, 1997, p. 4) creates poverty, just as a lack of economic well-being does, too. This means that welfare stems from the freedom to choose among valuable ways of living. Besides being complicated to operationalize, this approach is criticized for its focus on the opportunities instead of the outcomes achieved, which results in not accounting those poor who "fail to seize the opportunities offered" (Fleurbaey, 2002, p. 74). Those critics insist that it is the outcomes which are important for welfare and poverty and not the opportunity of different outcomes in the past.

Further approaches to the assessment of poverty can be summarized under the term social exclusion. It addresses the fact that the access of households to resources is partly determined by networks (Du Toit, 2007, p. 10). The theoretical concept referring to these resources is the one of 
social capital. According to Coleman (1988, p. S98), social capital "inheres in the structure of relations between actors and among actors". Similarly to capability, the concept of social capital, or the lack of it, which is referred to as social exclusion, is not easy to operationalize.

Waglé (2008b, p. 56) suggests treating the three concepts of economic well-being, capability and social exclusion as three relevant dimensions of poverty within one multidimensional assessment. This idea is adopted in our analysis.

After defining dimensions of poverty, the question remains to be answered, which criteria need to be fulfilled for someone to be regarded as poor; and accordingly, the criteria have to be defined. The main problem which arises when defining the criteria is that of consistency vs. specificity (Thorbecke, 2005, p. 8): consistency in terms of being applicable to any social context and thus allowing for comparability; and specificity as a consequence of the influence of social context on the evaluation of certain achievements. Parsons (1940) suggests individual preferences may be socially determined to a large extent. The application of an identical welfare function to several societies thus seems problematic. This may be a problem for the analysis presented here, which explores the development of poverty in Germany. In the 22 years of observation, there may have been certain changes in values. Nevertheless, the chosen indicators are expected to be relatively stable.

In terms of an overall concept, the one of relative poverty is applied, which means that deprivation in a given dimension is the absence of certain amount of welfare in that dimension relative to the overall distribution in society (Waglé, 2008b, p. 19). This is in contrast to an absolute concept of poverty, which is based on the definition of some basic needs. (Alkire 2002 gives an overview of several concepts of basic needs.)

\section{Empirical applications to Germany}

There is not much empirical work on multidimensional poverty measurement for Germany. The existing literature mainly focuses on the framework of relative deprivation in terms of an appropriate living standard. Therefore the empirical work on this concept can be seen as a detailed multidimensional measurement of one broad poverty dimension (for an overview see Groh-Samberg, 2009, pp. 66ff).

Böhnke and Delhey (1999) present an analysis on both the objective economic well-being dimension and on subjective measures that include indicators of social exclusion. They first compare the standard of living and the extent to which it depends on income, using data from the German Welfare Survey 1998 for Germany and the Breadline Britain Survey 1990 for Britain. 
The main result is that the negative relationship between income and the level of deprivation is weaker in Germany than in Britain (Böhnke and Delhey, 1999, p. 14). A consequence of this is that even when only considering the dimension of economic well-being, income cannot be seen as a perfect proxy indicator. They then introduce subjective satisfaction variables for several aspects of life, including a variable measuring individuals' satisfaction with possibilities of participating in social life. They find that the overall life satisfaction is determined more by subjective indicators and the standard of living than by income (Böhnke and Delhey, 1999, p. 18).

Merz and Rathjen (2009) apply a multidimensional concept of poverty with two dimensions, income and genuine leisure time, to determine the poor. In doing so, they introduce a basic part of the neoclassic household problem to the multidimensional poverty assessment debate. Using GSOEP 2002 data, they focus on working people and estimate the parameters of a CES population utility function by measuring the level of utility by the overall life satisfaction. The arguments in the population utility function, income and time, are operationalized as net equivalent income according to the modified OECD scale and typical weekday time for hobbies and other free-time activities (Merz and Rathjen, 2009, pp. 6-7). In further analysis, Merz and Rathjen use data from the German Time Use Study (GTUS) for 2001 and 2002. After calculating the poverty cutoff values for each dimension, they use the estimated CES function to obtain the respective utility level, which is then used as the multidimensional cutoff value. Given the three cutoffs, or poverty lines, they distinguish different types of poverty and analyze the socio-economic structure of each.

Instead of focusing on a detailed analysis of the structure of the multidimensionally identified poor, this paper aims to provide an overview of the development of multidimensional poverty. Therefore, it applies a methodology of multidimensional poverty measurement to Germany, introduced by Bourguignon and Chakravarty (2003), and Alkire and Foster (2008). The aim of this methodology is not only to identify the poor but also to aggregate the given information into a single index which allows comparisons of poverty over time and across countries and reveals information on the breadth, depth and severity of poverty.

\section{Empirical strategy}

\subsection{Identification}

The measurement of poverty is generally faced by the two problems of identification and aggregation: the identification of who is poor and the aggregation of information on the poor into 
an overall index (Sen, 1976, p. 219). In the context of multidimensional poverty measurement, this means one has to define criteria for identifying individual deprivation in multiple dimensions. Having defined criteria for each dimension, one has to decide, in how many dimensions an individual has to be deprived in order to be identified as poor (Alkire and Foster, 2008, p. 7).

The identification method used in the following analysis is taken from Alkire and Foster (2008) and is called "dual cutoff method of identification [original emphasis]" (Alkire and Foster, 2008, p. 8). In a first step, cutoff values $z_{j}$ are defined in each dimension $j$; and an individual $i$ is deprived in a dimension if his or her achievement $y_{i j}$ is smaller than the respective cutoff. The weighted count of the dimensions individual $i$ is deprived in is referred to as $c_{i}$. In a second step, a cutoff value $k$ across dimensions is defined; and an individual $i$ is identified as poor if $c_{i} \geq k$. This dual cutoff method is represented by the identification function:

(1) $\rho_{k}\left(y_{i}, z\right)=\left\{\begin{array}{lc}1, & \text { if } c_{i} \geq k \\ 0, & \text { else }\end{array}\right.$

Depending on the size of $k$, the identification function includes the two extremes of the so called union $(k=1)$ and intersection approach $(k=d$, where $d$ indicates the total number of dimensions, ). All values of $k$ between 1 and $d$ are referred to as intermediate dimension cutoff levels.

\subsection{Aggregation}

The easiest way of aggregating information on the poor into a single index is the headcount ratio, $H$, which simply counts the individuals identified as poor, $q$, and relates them to the total number of individuals, $n(H=q / n)$. The indices used in the analysis presented here are a family of multidimensional measures introduced by Bourguignon and Chakravarty (2003) and the adjusted FGT measures, the letters taken from the authors names, introduced by Alkire and Foster (2008). Both are based on the prominent unidimensional FGT poverty measure (Foster, Greer and Thorbecke 1984) and extend it in order to allow for multidimensional analysis. The main technical difference between the Bourguignon and Chakravarty indices and the adjusted FGT measures regards the property of additivity across dimensions, which the former do not satisfy in all cases. This results from allowing for different levels of substitutability between deprivations in different dimensions, as will be examined later on.

As the unidimensional FGT index builds the base for the adjusted FGT indices, the normalized poverty gap to the power $\alpha$ (which is a parameter of inequality aversion) is central to the index:

(2) $g_{i j}^{\alpha}=\left(\left(1-\frac{y_{i j}}{z_{j}}\right)_{+}\right)^{\alpha}$, where $y_{+}:=\max \{y, 0\}$ and $\alpha \geq 0$. 
Using the identification function above, a censored matrix of normalized gaps to the power $\alpha$ is obtained:

$$
\text { (3) } g^{\alpha}(k)=\left[g_{i j}^{\alpha} \rho_{k}\left(y_{i}, z\right)\right]
$$

In this matrix, the rows represent the individuals and the columns are the poverty dimensions. In the case of an individual being identified as poor in the first step, the normalized poverty gaps to the power $\alpha\left(g_{i j}^{\alpha}\right)$ are the entries of row $i$, which is replaced by a vector of zeros if $\rho_{k}\left(y_{i}, z\right)=0$. Consequently, the sum of all entries in the matrix $g^{\alpha}(k)$ is the sum of all normalized gaps to the power $\alpha$ experienced by the poor. This sum in relation to its highest possible value is defined as the adjusted FGT measure to the power $\alpha$ and referred to as $M_{\alpha}$ :

$$
\text { (4) } M_{\alpha}=\frac{\left|g^{\alpha}(k)\right|}{n d}
$$

where $|y|$ is defined as the sum of all elements in the matrix $y ; n$ is the total number of observations; and $n d$ is the highest possible sum of normalized gaps to the power $\alpha$.

The three values of $\alpha$ used in the following analysis $(0,1,2)$ illustrate important properties of the adjusted FGT measures very well. With an $\alpha$-value of 0 , the adjusted headcount ratio $M_{0}$ is obtained, with $g^{0}(k)$ counting the number of deprivations experienced by the poor. Therefore, $M_{0}$ is sensitive to the frequency of poverty, as is the case in the Headcount ratio, and also to the breadth of poverty: $M_{0}$ increases if a poor individual becomes deprived in an additional dimension. With $\alpha$ equal to 1 , the adjusted poverty gap $M_{1}$ is obtained, which, in addition to being sensitive to frequency and breadth of poverty, is sensitive to the depth of poverty: $M_{1}$ increases if a poor individual becomes more deprived in a deprived dimension. Setting $\alpha$ to 2 , yields the adjusted squared poverty gap $M_{2}$, which assigns greater weight to higher deprivations and thus is sensitive to the severity of poverty. Technically speaking $M_{0}, M_{1}$ and $M_{2}$ fulfill the property of "dimensional monotonicity" and $M_{1}$ and $M_{2}$ fulfill an additional property of "monotonicity". Dimensional monotonicity means that a poverty index should decline if a poor individual's situation improves, and as a consequence, he or she is no longer deprived in one of the dimensions. Monotonicity means that a poverty index should fall if a poor individual becomes less deprived in any dimension (Alkire and Foster 2008, 16).

For further analysis, the adjusted FGT indices can be subdivided into several subindices. $M_{0}$ can be divided into the headcount ratio, $H=\frac{q}{n}$, and the average deprivation share among the poor, $A=\frac{\left|g^{0}(k)\right|}{q d}\left(M_{0}=H A\right)$. In addition, $M_{1}$ can be divided into the average gap among the poor $G=\frac{\left|g^{1}(k)\right|}{\left|g^{0}(k)\right|}\left(M_{1}=H A G\right)$. Finally, replacing the average gap $G$ by the average severity $S=\frac{\left|g^{2}(k)\right|}{\left|g^{0}(k)\right|}$ 
$\left(M_{2}=H A S\right)$ yields $M_{2}$. As it will become clear later, relevant information on the situation of the poor can be extracted from these subindices.

As previously mentioned, the BC-measures allow for different levels of substitutability between the dimensions, which means that the degree to which a higher deprivation in one dimension can be substituted by smaller deprivation in another can vary. Due to its functional form, it is difficult to "control" for more than two dimensions in the index. Therefore, the following analysis applies the BC-measure for two dimensions. The index used consists of a CES function and can be written as:

$$
\text { (5) } P_{\alpha}^{\theta}(X ; z)=\frac{1}{n} \sum_{i=1}^{n}\left(a_{1}\left(g_{i 1}^{1}\right)^{\theta}+a_{2}\left(g_{i 2}^{1}\right)^{\theta}\right)^{\frac{\alpha}{\theta}}
$$

where $g_{i j}^{1}$ is as explained above, $a_{1}$ and $a_{2}$ are the weights of the dimensions, and the parameter $\theta>1$. The CES function describes concave iso-poverty curves in the space of the deprivations, which goes along with convex iso-utility curves in the space of the achievements on the dimen-

sions. The elasticity of substitution is $\sigma=\frac{1}{1-\theta}$. The higher $\sigma$, the better the deprivation in one dimension can be substituted by achievement in the other dimension. When $\theta$ tends towards 1 , $\sigma$ tends towards infinity, and thus the attributes are perfect substitutes and the BC-measures resemble the adjusted FGT-measures. The cases that differ from the adjusted FGT family are those of levels of substitutability worse than in the case of perfect substitutability. It is clear to see that the BC-index allows for substitution of strong deprivation in one dimension by achievement in another dimension only as long as the achievement is not too large: if an individual is not deprived in the "better" dimension, the index only takes the deprived dimension into account. For the dimensions of education and income, this means, for example, that a "dumb" millionaire is treated as poor because the identification method used is "union" $(k=$ 1).

\subsection{Dataset}

The following analysis of multidimensional poverty in Germany is based on household micro data provided by the German Socio-Economic Panel Study (GSOEP) for 1985 to 2007. GSOEP was started in 1984 with a representative set of around 4,500 households and has since collected annual samples, which in 2007 numbered around 12,000. A sample for East Germany has been included since 1990. Each wave delivers information on a range of subjects, including occupation, income, taxes, household composition, health status, education, satisfaction or political interests (SOEP Group, 2001, p. 9). 


\subsection{Dimensions and Operationalization}

The dimensions selected for measuring poverty are economic well-being and capability, whereby the indicators for the latter can also be interpreted as indicators for the dimension of social exclusion. This is because, following Waglé (2008b, p. 65), the indicators to measure the quality of life in capability terms are selected as proxies for the degree of freedom an individual has in affecting the valuable functionings. In the first part of the analysis, education is used as an indicator for poverty according to the capability approach "since its entire concept revolves around staying informed and being able to make appropriate decisions involving choices" (Waglé, 2008 b, p. 140). The second part adds health as a further indicator. The household income is used as an indicator of economic well-being.

Health can be seen as an indirect indicator of social exclusion because a person suffering from bad health has limited possibilities to participate in social life. A similar argument can be given for education: with higher education comes, for example, the possibility to participate in specific cultural events or a greater likelihood of participating actively in the political process. Thus, both indicators according to the capability approach can be interpreted as proxy indicators of social exclusion just as income is interpreted as proxy for economic well-being.

The GSOEP variable used to operationalize household income is the post government household income in each wave, which is surveyed retrospectively for the antecedent year. It includes all taxes and transfers and thus indicates the household's disposal income. In order to compare households of different size, the adjusted household income is calculated using the modified OECD equivalence scale, in which household income is divided by the weighted sum of household members, calculated by assigning a weight of 1 to the household head, 0.5 to each adult member and 0.3 to each child. Although the unit of observation is the individual, household income is assumed to be a more appropriate measure of the economic situation of the individual. This is because the overall financial situation of an individual is dependent not only on personal income but also on the incomes of all household members.

Information on the number of years of education is used to operationalize the corresponding indicator. The advantage of using the number of years rather than, for instance, the highest educational degree, is that the poverty gap can then be properly interpreted. Health is operationalized as the satisfaction with health at the time of the survey on a scale from 0 , "completely dissatisfied", to 10, "completely satisfied". In order to demonstrate the importance of a proper operationalization of health, the number of nights spent in hospital is used for a robustness check of the measures. Similarly to income, it is surveyed retrospectively. Of course, nights in 
hospital are not as good an indicator for the health status as satisfaction with health. For example, the nights in hospital do not take into account ambulant treatment of chronic diseases. Furthermore, the kind of health insurance a patient has could be decisive on whether he or she spends a night in hospital - and that would be more an indicator for economic wealth than for health. Nevertheless, the variable is used here because of its cardinal character, which allows the application of the presented methodology.

For the calculation of the indices of each year, only those observations in which values are found in all the dimension variables are considered.

\section{Empirical results}

\subsection{Influence of substitutability on the development of poverty}

This first part of the analysis mainly explores the influence of different levels of substitutability between shortfalls on poverty dimensions; whereby shortfalls mean the standardized poverty gaps. The indicators used to measure poverty are income and education operationalized as explained above. Both the adjusted FGT and the BC indices are applied. With two dimensions, the adjusted FGT measure becomes:

(6) $\quad M_{\alpha}=\frac{1}{n} \sum_{i=1}^{n}\left(a_{1} g_{i 1}^{\alpha}+a_{2} g_{i 2}^{\alpha}\right)$,

and the BC-index remains unchanged as in equation (5): $P_{\alpha}^{\theta}(X ; z)=\frac{1}{n} \sum_{i=1}^{n}\left(a_{1}\left(g_{i 1}^{1}\right)^{\theta}+\right.$ $\left.a_{2}\left(g_{i 2}^{1}\right)^{\theta}\right)^{\frac{\alpha}{\theta}}$

In the case of $\theta=1$ and $\alpha=1$, the two indices are identical, as well as in the case of $\theta=2$ and $\alpha=2$. In these two specific cases, the BC-index resembles the adjusted poverty gap and the adjusted squared poverty gap, respectively. In the first case $(\theta=1, \alpha=1)$, the two shortfalls are perfect substitutes; and in the second case $(\theta=2, \alpha=2)$, the squared shortfalls are perfect substitutes. The shortfalls are described by an elasticity of substitution of -1 . Given the value of $\alpha$, an increase of $\theta$ worsens the elasticity of substitution; when $\theta$ tends towards infinity, the elasticity of substitution tends towards zero, and thus the shortfalls become perfect complements.

The analysis compares $\theta$-values of 1 , the case of perfect substitutability, to values of 2 and 5 , worse substitutability, and to perfect complements $(\theta \rightarrow \infty)$ for the $\alpha$-values of 0,1 and 2 . This results in seven measures plus the headcount ratio. The dimensional weights are set equal to $a_{1}=a_{2}=0.5$. 
Following the concept of relative poverty and the European Union standard, the poverty line for income is set at 60 percent of the median income (Glennerster, 2002, p. 87). The poverty line for education is set at a constant of nine years because this is the length of compulsory schooling in most federal states in Germany.

Table 1 depicts the unidimensional poverty levels as headcounts. While income poverty increased from 1985 to 2007, poverty decreased with respect to education. The share of the population poor in terms of income increased from 11.42 percent in 1985 to 13.47 percent in 2007. When examining the numbers presented in Table 1 , one can see that this income poverty rate is not constantly increasing, with the lowest value at 10.22 percent in 1998. Regarding education, there is an almost constant decrease in the poverty rate from 4.19 percent in 1985 to 2.44 percent in 2007. At 2.25 percent, the population share of those with fewer than nine years of formal education is the lowest in 2000 . 
Table 1: Unidimensional Poverty (Income and Education)

\begin{tabular}{l|llllllll}
\hline \hline Year & 1985 & 1986 & 1987 & 1988 & 1989 & 1990 & 1991 & 1992 \\
\hline $\begin{array}{l}\text { Income headcount } \\
\text { Education head- }\end{array}$ & .1142 & .1124 & .1069 & .1189 & .1088 & .1133 & .1324 & .1193 \\
count & .0419 & .0411 & .0402 & .0394 & .0438 & .0358 & .0359 & .0375 \\
& & & & & & & & \\
Year & 1993 & 1994 & 1995 & 1996 & 1997 & 1998 & 1999 & 2000 \\
\hline $\begin{array}{l}\text { Income headcount } \\
\text { Education head- }\end{array}$ & .1164 & .1184 & .1187 & .1069 & .1068 & .1022 & .1042 & .1111 \\
count & & & & & & & & \\
Year & .0389 & .0424 & .0421 & .0375 & .0336 & .0305 & .0290 & .0225 \\
\hline $\begin{array}{l}\text { Income headcount } \\
\text { Education head- }\end{array}$ & .1262 & .1272 & .1272 & .1335 & .1379 & .1357 & .1347 & \\
count & & & & & & & & \\
\hline \hline
\end{tabular}

Source: Own calculations based on GSOEP data.

When comparing the eight multidimensional indices with each other, we are not mainly interested in the absolute values but the development of the indices over time. In order to investigate this issue, the correlations of the indices are shown in Table 2. One can see that the correlation between the headcount and adjusted headcount is almost perfect; whereas both of these indices correlate worse with the four measures that take the standardized gap into account, and even worse with the two indices that use the squared gap. Within the groups of indices using the gap or the squared gap, correlations are almost perfect. All six indices that use either the gap or the squared gap correlate very strongly with each other. At this point, one might already conclude that substitutability does not have a large influence, since the six relevant indices overall move in the same direction. 
Table 2: Correlations of adjusted FGT and BC indices

\begin{tabular}{c|cccccccc}
\hline \hline & $H$ & $M_{0}$ & $M_{1}=P_{1}^{1}$ & $P_{1}^{2}$ & $P_{1}^{5}$ & Compl & $M_{2}=P_{2}^{2}$ & $P_{2}^{5}$ \\
\hline$H$ & 1.0000 & & & & & & & \\
$M_{0}$ & .9917 & 1.0000 & & & & & \\
$M_{1}$ & & & & & & & & \\
$=P_{1}^{1}$ & .7478 & .7924 & 1.0000 & & & & & \\
$P_{1}^{2}$ & .7646 & .8036 & .9987 & 1.0000 & & & & \\
$P_{1}^{5}$ & .7694 & .8063 & .9977 & .9998 & 1.0000 & & & \\
Compl & .7702 & .8067 & .9974 & .9997 & 1.0000 & 1.0000 & & \\
$M_{2}$ & & & & & & & & \\
$=P_{2}^{2}$ & .3246 & .3813 & .8549 & .8451 & .8418 & .8413 & 1.0000 & \\
$P_{2}^{5}$ & .3271 & .3819 & .8545 & .8456 & .8427 & .8422 & .9998 & 1.0000 \\
\hline \hline
\end{tabular}

Source: Own calculations based on GSOEP data.

In order to obtain a more detailed grasp of the development of the indices, Tables 3 to 5 show their values from 1985 to 2007. The indices are divided into three groups, depending on which value of $\alpha$ they use. Within each group, one has to check whether the changing level of $\theta$ has an influence on the development of the measure, in order to verify whether a changing elasticity of substitution has a substantial effect on the conclusions drawn from an index.

By calculating 95 percent-confidence intervals for the measures for each year, it can be analyzed whether an index changes significantly over time. The confidence intervals are calculated using a bootstrap method with 1,000 repetitions. Table 3 shows the headcount and the adjusted headcount with the calculated confidence intervals for 1985 to 2007. For easier comprehension, the development of the indices is shown graphically in Figure A1 in the appendix.

The population share of individuals defined as poor lies between 13.88 and 15.45 percent in 1985. At the end of the 80s and the beginning of the 90s, there is an upward trend, peaking in 1991, where the confidence interval of the poverty headcount ranges between 15.73 and 17.18 percent. This is significantly higher than in all other observed years, except for 1992, when the confidence interval overlaps with the one of 1991. After the peak in the early 90s, the poverty headcount declines in the following years, reaching a minimum around the end of the same decade: the confidence interval for 2000 ranges between 11.70 and 12.76 percent, which significantly differs from 2001 and later years as well as from 1995 and earlier years. In the years following 2000, there is an increase back to a poverty headcount of around 14 percent in 2007. The 
dimensional adjustment of the headcount to $M_{0}$ does not lead to other information regarding the development of the poverty rate, which is to be expected from the very high correlation of the two indices. As for the headcount, the highest value for $M_{0}$ is in 1991, with the lower limit of the confidence interval at.0815. Measured poverty is lowest in 2000, with an upper limit of the confidence interval at .0668. Poverty is similar at the beginning and end of the period of observation, with values around .0772 and .0749 , respectively.

Table 3: Headcount and adjusted headcount, with confidence intervals (income and education)

\begin{tabular}{ccccccc}
\hline \hline & \multicolumn{3}{c}{$H$} & & & $M_{0}$ \\
& lci & estimate & uci & lci & estimate & uci \\
\hline 1985 & .13879 & .14660 & .15447 & .07302 & .07716 & .08134 \\
1986 & .13540 & .14312 & .15094 & .07057 & .07459 & .07867 \\
1987 & .12799 & .13616 & .14385 & .06721 & .07149 & .07554 \\
1988 & .13816 & .14591 & .15414 & .07278 & .07681 & .08118 \\
1989 & .13266 & .14089 & .14926 & .07000 & .07440 & .07888 \\
1990 & .13755 & .14669 & .15530 & .07257 & .07736 & .08196 \\
1991 & .15729 & .16423 & .17178 & .08153 & .08514 & .08908 \\
1992 & .14264 & .15060 & .15825 & .07433 & .07845 & .08243 \\
1993 & .13809 & .14528 & .15262 & .07251 & .07626 & .08010 \\
1994 & .13978 & .14697 & .15453 & .07416 & .07812 & .08223 \\
1995 & .14045 & .14804 & .15540 & .07434 & .07832 & .08220 \\
1996 & .12442 & .13231 & .14030 & .06527 & .06933 & .07344 \\
1997 & .12314 & .13085 & .13876 & .06450 & .06855 & .07270 \\
1998 & .11531 & .12234 & .12944 & .06048 & .06415 & .06787 \\
1999 & .11717 & .12447 & .13179 & .06142 & .06524 & .06907 \\
2000 & .11697 & .12222 & .12761 & .06117 & .06394 & .06679 \\
2001 & .12975 & .13554 & .14132 & .06844 & .07153 & .07464 \\
2002 & .13058 & .13728 & .14370 & .06932 & .07295 & .07643 \\
2003 & .12895 & .13537 & .14198 & .06841 & .07188 & .07546 \\
2004 & .13104 & .13784 & .14500 & .06992 & .07360 & .07750 \\
2005 & .13611 & .14391 & .15139 & .07295 & .07735 & .08158 \\
2006 & .13951 & .14644 & .15360 & .07352 & .07738 & .08136 \\
2007 & .13337 & .14035 & .14739 & .07105 & .07487 & .07880 \\
\hline \hline
\end{tabular}

Source: Own calculations based on GSOEP data. 
Table 4 and Figure A2 show those measures that take into account the depth of deprivation in each dimension. As expected from the almost perfect correlations between the four relevant indices, the detailed analysis of the development of the indices reveals no major differences that could be interpreted as an influence of the elasticity of substitution. The similarity in the development of the four indices to the headcount and adjusted headcount deserves a mention. Nevertheless, while the latter have a downward trend in the middle of the 90s, the poverty measures using an $\alpha$-value of 1 peak in 1995, which significantly differs from the values in 1996 and 1993. Even though the share of people treated as poor declines $\left(H\right.$ and $\left.M_{0}\right)$, the poverty indices sensitive to the depth of poverty rise: one can interpret this as an indicator for a worsening of the situation of those who remained or became poor in the middle of the 90s. As mentioned, a deeper analysis of this issue follows in Section 5.3. The lowest poverty is measured for 1998, after which there follows an upward trend. 
Table 4: Measures using $\alpha=1$, with confidence intervals (income and education)

\begin{tabular}{|c|c|c|c|c|c|c|c|c|c|c|c|c|}
\hline & & $M_{1}=P_{1}^{1}$ & & & $P_{1}^{2}$ & & & $P_{1}^{5}$ & & & Compl & \\
\hline & lci & estimate & $u c i$ & $l c i$ & estimate & $u c i$ & $l c i$ & estimate & uci & $l c i$ & estimate & uci \\
\hline 1985 & .01595 & .01725 & .01854 & .02197 & .02376 & .02553 & .02680 & .02899 & .03115 & .01537 & .01662 & .01786 \\
\hline 1986 & .01518 & .01642 & .01766 & .02102 & .02273 & 02445 & .02571 & .02780 & .02990 & 01475 & 01595 & 01716 \\
\hline 1987 & .01480 & .01606 & .01729 & .02042 & .02216 & .02387 & .02494 & .02707 & .02916 & .01430 & .01553 & .01673 \\
\hline 1988 & .01512 & .01633 & .01756 & .02085 & .02253 & .02423 & .02546 & .02752 & .02960 & .01460 & .01579 & .01698 \\
\hline 1989 & .01547 & .01684 & .01826 & .02127 & .02313 & .02505 & .02596 & .02823 & .03057 & .01489 & .01619 & .01754 \\
\hline 1990 & 01596 & .01724 & .01853 & .02201 & .02376 & .02554 & .02688 & .02902 & .03120 & .01542 & .01665 & 01790 \\
\hline 1991 & .01661 & .01769 & .01879 & .02307 & .02456 & .02608 & .02825 & .03008 & .03194 & .01621 & .01726 & .01832 \\
\hline 1992 & .01566 & .01679 & .01793 & .02168 & .02325 & 02483 & .02650 & .02842 & .03036 & .01519 & .01630 & .01741 \\
\hline 1993 & .01483 & .01598 & .01711 & .02039 & .02197 & .02353 & .02487 & .02680 & .02870 & .01426 & .01537 & .01646 \\
\hline 1994 & .01717 & .01847 & .01983 & .02355 & .02532 & .02716 & .02871 & .03087 & .03312 & .01646 & .01770 & .01899 \\
\hline 1995 & .01782 & .01929 & .02076 & .02448 & .02652 & .02855 & .02987 & .03237 & .03486 & .01712 & .01856 & .01999 \\
\hline 1996 & .01512 & .01641 & .01772 & .02082 & .02263 & .02445 & .02542 & .02764 & .02987 & .01458 & .01585 & .01714 \\
\hline 1997 & 01490 & .01621 & .01758 & .02059 & .02240 & .02430 & .02515 & .02737 & .02970 & .01443 & .01570 & .01704 \\
\hline 1998 & .01300 & .01410 & .01518 & .01791 & 01942 & .02091 & .02185 & .02370 & .02552 & .01253 & .01358 & .01463 \\
\hline 1999 & .01352 & .01474 & .01600 & .01863 & .02032 & .02206 & .02273 & .02480 & .02693 & 01303 & .01422 & .01545 \\
\hline 2000 & .01391 & .01474 & .01556 & 01922 & .02036 & .02149 & .02348 & .02487 & .02625 & .01347 & .01426 & .01505 \\
\hline 2001 & .01582 & .01681 & .01781 & .02180 & .02316 & .02454 & .02660 & .02828 & .02996 & .01525 & .01621 & .01718 \\
\hline 2002 & .01592 & .01699 & .01808 & .02185 & .02330 & .02480 & .02663 & .02841 & .03025 & .01527 & .01629 & .01734 \\
\hline 2003 & .01556 & .01670 & .01784 & 02140 & .02298 & 02455 & .02611 & .02804 & .02997 & .01497 & .01608 & .01719 \\
\hline 2004 & .01520 & .01630 & .01742 & .02089 & .02240 & .02395 & .02545 & .02730 & .02919 & .01458 & .01564 & .01672 \\
\hline 2005 & .01677 & .01802 & .01932 & .02294 & .02464 & .02641 & .02792 & .03000 & .03216 & .01600 & .01719 & .01843 \\
\hline 2006 & .01688 & .01814 & .01940 & .02330 & .02502 & .02674 & .02847 & .03057 & .03268 & .01633 & .01754 & .01875 \\
\hline 2007 & .01522 & .01636 & .01752 & 02091 & .02244 & 02401 & .02549 & .02736 & .02927 & .01462 & .01569 & .01678 \\
\hline
\end{tabular}

Source: Own calculations based on GSOEP data.

Table 5 and Figure A3 present the development of the two indices sensitive to the severity of poverty. As for the six measures presented so far, the poverty at the beginning and end of the observation period does not differ significantly. Similar to the four indices using $\alpha=1$, the two measures using $\alpha=2$ peak in the middle of the 90 s. Consequently, this period is analyzed in Section 5.3. As for the other indices, poverty is lowest towards the end of the 90s, reaching a minimum in 1998, again followed by an upward trend. The value of $\theta$, and thus the elasticity of substitution, has no influence on the development of the measured poverty. 
Table 5: Measures using $\alpha=2$, with confidence intervals (income and education)

\begin{tabular}{|c|c|c|c|c|c|c|}
\hline & \multicolumn{3}{|c|}{$M_{2}=P_{2}^{2}$} & \multicolumn{3}{|c|}{$P_{2}^{5}$} \\
\hline & $l c i$ & estimate & $u c i$ & $l c i$ & estimate & $u c i$ \\
\hline 1985 & .00554 & .00632 & .00710 & .00824 & .00942 & .01059 \\
\hline 1986 & .00511 & .00582 & .00654 & .00762 & .00870 & .00979 \\
\hline 1987 & .00506 & .00579 & .00653 & .00753 & .00865 & .00975 \\
\hline 1988 & .00486 & .00548 & .00612 & .00723 & .00817 & .00912 \\
\hline 1989 & .00535 & .00616 & .00698 & .00796 & .00916 & .01039 \\
\hline 1990 & .00518 & .00585 & .00654 & .00770 & .00872 & .00975 \\
\hline 1991 & .00512 & .00564 & .00616 & .00766 & .00844 & .00922 \\
\hline 1992 & .00495 & .00562 & .00629 & .00739 & .00840 & .00941 \\
\hline 1993 & .00465 & .00528 & .00592 & .00689 & .00785 & .00880 \\
\hline 1994 & .00612 & .00694 & .00779 & .00909 & .01032 & .01158 \\
\hline 1995 & .00664 & .00769 & .00875 & .00987 & .01146 & .01305 \\
\hline 1996 & .00537 & .00611 & .00686 & .00799 & .00910 & .01024 \\
\hline 1997 & .00529 & .00610 & .00694 & .00789 & .00912 & .01038 \\
\hline 1998 & .00432 & .00490 & .00547 & .00642 & .00729 & .00815 \\
\hline 1999 & .00456 & .00536 & .00617 & .00678 & .00798 & .00921 \\
\hline 2000 & .00495 & .00537 & .00580 & .00738 & .00802 & .00866 \\
\hline 2001 & .00581 & .00643 & .00705 & .00866 & .00960 & .01053 \\
\hline 2002 & .00574 & .00632 & .00693 & .00852 & .00940 & .01030 \\
\hline 2003 & .00574 & .00643 & .00712 & .00855 & .00959 & .01063 \\
\hline 2004 & .00510 & .00569 & .00629 & .00758 & .00847 & .00938 \\
\hline 2005 & .00581 & .00645 & .00711 & .00862 & .00957 & .01056 \\
\hline 2006 & .00619 & .00687 & .00756 & .00924 & .01027 & .01130 \\
\hline 2007 & .00508 & .00567 & .00627 & .00755 & .00843 & .00932 \\
\hline
\end{tabular}

Source: Own calculations based on GSOEP data.

\subsection{Influence of substitutability on the robustness of the measures}

The elasticity of substitution has so far not had any influence worth mentioning. For all values of $\alpha$, the corresponding indices developed almost equally. Nevertheless, there may be differences with respect to robustness. This is now to be examined. One of the robustness checks conducted concerns a change in the poverty threshold for income from 60 to 80 percent of the median. In a second robustness check, the dimensional weights are changed from an equal to a 
greater emphasis on income. The underlying idea is that income may play a greater role for present welfare; whilst higher education increases the opportunity of achieving higher future welfare.

One result of a change in the income poverty line from 60 to 80 percent of the median is, of course, an increase of unidimensional poverty in that dimension. The correlations of the multidimensional indices are given in Table 6 . As before, the indices of each $\alpha$-group correlate almost perfectly with each other. Compared to the original income cutoff, the multidimensional headcount now correlates more strongly with the indices using the normalized gap or the squared normalized gap. An analysis of the development of the multidimensional indices leads to results very similar to the original analysis; since the focus of this section is the robustness of the measures, there is no detailed analysis presented here. Tables A1-A3 in the appendix show the values of the measures, including the bootstrap confidence intervals.

Table 6: Correlations of indices with poverty line for income at 80 percent of median

\begin{tabular}{c|cccccccc}
\hline \hline & $H$ & $M_{0}$ & $M_{1}=P_{1}^{1}$ & $P_{1}^{2}$ & $P_{1}^{5}$ & Compl & $M_{2}=P_{2}^{2}$ & $P_{2}^{5}$ \\
\hline$H$ & 1.0000 & & & & & & & \\
$M_{0}$ & .9902 & 1.0000 & & & & & & \\
$M_{1}$ & & & & & & & & \\
$=P_{1}^{1}$ & .8532 & .8329 & 1.0000 & & & & & \\
$P_{1}^{2}$ & .8472 & .8196 & .9985 & 1.0000 & & & & \\
$P_{1}^{5}$ & .8429 & .8128 & .9973 & .9998 & 1.0000 & & & \\
Compl & .8414 & .8107 & .9969 & .9997 & 1.0000 & 1.0000 & & \\
$M_{2}$ & & & & & & & & \\
$=P_{2}^{2}$ & .5084 & .4774 & .8690 & .8738 & .8767 & .8780 & 1.0000 & \\
$P_{2}^{5}$ & .5000 & .4655 & .8634 & .8697 & .8732 & .8746 & .9996 & 1.0000 \\
\hline \hline
\end{tabular}

Source: Own calculations based on GSOEP data.

In order to examine the sensitivity of the measures to the change in the income poverty threshold, the correlation between each measure before and after the change is calculated, which is shown in Table 7 . The headcounts and the adjusted headcounts before and after the change in the poverty line correlate very strongly, at 0.9020 and 0.9126 , respectively. The four indices using the standardized poverty gap $(\alpha=1)$ correlate strongly with their counterparts after the change. From this one can conclude that the indices using $\alpha=1$ are robust to the cutoff change on the income dimension. Indices using the squared standardized gap react a little more sensi- 
tively to a changing dimensional cutoff value but can still be considered robust. In all cases, the level of the elasticity of substitution has no influence worth mentioning. Together with the fact that they correlate better with the six indices $M_{1}$ to $P_{1}^{5}$, the higher robustness of $H$ and $M_{0}$ indicates that in the case of a higher income cutoff, the former six indices adapt to the latter. Following an examination of the information given in Tables A1 to A3, this consideration is confirmed.

Table 7: Sensitivity to a change of income poverty threshold

\begin{tabular}{|c|c|c|c|c|c|c|c|c|}
\hline & $H$ & $M_{0}$ & $M_{1}=P_{1}^{1}$ & $P_{1}^{2}$ & $P_{1}^{5}$ & Compl & $M_{2}=P_{2}^{2}$ & $P_{2}^{5}$ \\
\hline $\begin{array}{l}\text { Correlation with the } \\
\text { same }\end{array}$ & .9020 & .9126 & 8468 & 8355 & .8310 & .8294 & .8007 & .7938 \\
\hline index after change & & & & & & & & \\
\hline
\end{tabular}

Source: Own calculations based on GSOEP data.

Taking the original income poverty line of 60 percent of the median, the indices are controlled for their sensitivity to a change of the dimensional weights as described earlier in this section. The weight of income is set to 0.7 and the weight of education to 0.3 . This of course has no influence on the poverty headcount, $H$, since the identification of poverty remains the same. At the same time, the development of the adjusted headcount resembles the development of the unidimensional income poverty rate more closely: while the two dimensions, $M_{0}$ and the unidimensional income poverty rate, correlate at 0.5689 when equally weighted, they correlate at 0.8769 when the weight of the income dimension set to 0.7 . Like the income headcount, $M_{0}$ reaches its minimum in 1998. However, the value does not significantly differ from the values between 1996 and 2000, and so the substantial interpretation of the development of the index remains as with the equal weights. The same holds for the other measures tested, which resemble the original situation even more closely. Detailed information is given in Tables A4 and A5.

The results of the robustness checks are shown in Table 8. In contrast to the first robustness check, the level of substitutability has some influence on the sensitivity of the measures to the change of dimensional weights. Within the group of indices using the normalized poverty gap, $M_{1}=P_{1}^{1}$ appears to be less robust than $P_{1}^{2}$, which in turn seems to be less robust than $P_{1}^{5}$, which correlates almost perfectly with its counterpart. The same holds for the two indices using $\alpha=2$. Thus, one might conclude that a decreasing elasticity of substitution goes hand in hand with increasing robustness. Since the correlations only use the GSOEP-sample values and do not take the confidence intervals into account, which to a large extent overlap, one must not overinterpret this. Overall, the level of substitutability between poverty dimensions has much less 
influence on the measurement of multidimensional poverty than one might expect, and has no influence in almost all of the situations tested.

Table 8: Sensitivity to a change of dimensional weights

\begin{tabular}{l|cccccc}
\hline \hline & $M_{0}$ & $M_{1}=P_{1}^{1}$ & $P_{1}^{2}$ & $P_{1}^{5}$ & $M_{2}=P_{2}^{2}$ & $P_{2}^{5}$ \\
\hline $\begin{array}{l}\text { Correlation with the } \\
\text { same }\end{array}$ & & & & & & \\
index after change & .8853 & .8782 & .9504 & .9899 & .9774 & .9940 \\
\hline \hline
\end{tabular}

Source: Own calculations based on GSOEP data.

\subsection{Taking a third attribute into account}

This part of the analysis includes health as a third indicator of poverty and applies the adjusted FGT family as given by equation (2). The same $\alpha$-values as before are used. The sensitivity of the indices to the changing operationalization of health is explored. For further analysis of the results, the indices are divided into their subindices as explained in Section 4.2. In accordance with the identification method, an intermediate approach is applied, which means that an individual has to be deprived in two of the three dimensions in order to be counted as poor, as suggested by Alkire and Foster (2008, p. 8).

The poverty threshold for health is defined as the median. In the case of health being operationalized by the self-reported satisfaction with health, the application of the adjusted FGT measures is limited, since, strictly speaking, the variable is ordinal.. The application of the adjusted poverty gap, $M_{1}$, and the adjusted squared poverty gap, $M_{2}$, is restricted due to the problem of interpreting the poverty gap in the ordinal case. As they do not make use of the gap, the headcount ratio and the adjusted headcount $M_{0}$ can be applied thoroughly The calculation and use of the standardized poverty gap is unproblematic in the case of health being operationalized by the number of nights spent in hospital. In order to apply the presented methodology to the variable, it is reversed for each year: for each observation the number of nights is subtracted from the highest number in the respective year. In that way, the observation with the highest number of nights is assigned a zero and an observation with zero nights is assigned the highest number.

When using both cardinal and ordinal variables, as done in the analysis which uses two cardinal variables for income and education, Alkire and Foster $(2008$, p. 23) suggest a hybrid case. In the censored deprivation matrix, $g^{\alpha}(k)$, as presented in equation (2), the entries remain the same for cardinal variables but are changed for ordinal variables: for cardinal variables, poor individuals are assigned a value of 0 if not deprived; however, they are assigned a value of 1 if 
deprived in the ordinal variable, instead of the normalized gap $g_{i j}^{\alpha}$. The measures are calculated using this new matrix. However, this leads to a technical problem of weighting: the ordinal variables are automatically weighted more in all $M_{\alpha}$-indices with $\alpha>0$. This is because the value of 1 is the maximum possible value of the standardized gap. When using this hybrid type one has to define weights that try to solve the problem. This problem is seen as a minor problem in the analysis, and since the satisfaction with health variable has 11 categories, it is interpreted as cardinal.

The unidimensional poverty rates are shown in Table 9. Apart from a few minor fluctuations, the poverty headcount is stable for both operationalizations of health. It has to be mentioned that at around 40 percent, the share of individuals deprived with respect to satisfaction with health is higher than the share of individuals deprived with respect to nights spent in hospital, which is stable at around 12 percent. Since all three indicators (income, education and health) have the same weight in the multidimensional measure, this will lead to differences in the respective measures for the two operationalizations. However, since we did not look at the poverty gaps here, one cannot already conclude on how the two measures using the normalized gap and the squared gap, $M_{1}$ and $M_{2}$, will differ in their development over time.

Table 9: Unidimensional poverty headcounts (satisfaction with health and nights in hospital)

\begin{tabular}{l|cccccccc}
\hline \hline Year & 1985 & 1986 & 1987 & 1988 & 1989 & 1990 & 1991 & 1992 \\
\hline Satisfaction with health & .4045 & .4094 & .4126 & .4258 & .4358 & .4265 & .4323 & .4013 \\
Nights in hospital & .1210 & .1225 & .1238 & .1227 & n.o. $^{1}$ & .1055 & .1201 & n.o. \\
& & & & & & & & \\
Year & 1993 & 1994 & 1995 & 1996 & 1997 & 1998 & 1999 & 2000 \\
\hline Satisfaction with health & .4375 & .4498 & .4415 & .4476 & .4440 & .4288 & .4329 & .4028 \\
Nights in hospital & .1299 & .1266 & .1267 & .1271 & .1263 & .1309 & .1237 & .1257 \\
& & & & & & & & \\
Year & 2001 & 2002 & 2003 & 2004 & 2005 & 2006 & 2007 & \\
\hline Satisfaction with health & .4006 & .4169 & .4146 & .4393 & .4323 & .4258 & .4340 & \\
Nights in hospital & .1247 & .1232 & .1276 & .1193 & .1251 & .1227 & .1196 & \\
\hline \hline
\end{tabular}

Notes: ${ }^{1}$ No observations for number of nights in hospital for 1989 and 1992.

Source: Own calculations based on GSOEP data.

In order to demonstrate the sensitivity of the adjusted FGT measures to the changing operationalization, the correlations between the indices of both operationalizations are calculated and 
presented in Table 10. The lower the $\alpha$-value an index uses, the more robust it is towards the changing operationalization of health: the two headcounts, $H$, correlate at 0.7585 , while $M_{0}$ and $M_{1}$ correlate with their counterparts of the different operationalization at 0.7560 and 0.6062 , respectively. $M_{2}$ reacts the most sensitively to the different operationalizations: the two measurements of $M_{2}$ correlate at only 0.5477 . Therefore, it can be concluded that the depth and severity of poverty in the two operationalizations develops differently.

Table 10: Sensitivity to changing operationalization of health

\begin{tabular}{l|cccc}
\hline \hline & $H$ & $M_{0}$ & $M_{1}$ & $M_{2}$ \\
\hline $\begin{array}{l}\text { Correlation with the } \\
\text { same }\end{array}$ & .7585 & .7560 & .6062 & .5477 \\
index after change & & & & \\
\hline \hline
\end{tabular}

Source: Own calculations based on GSOEP data.

Moving to a more detailed analysis of poverty, Table 11 shows the development of the adjusted FGT measures for the operationalization satisfaction with health; income and education are operationalized as before and the cutoffs are at 60 percent of the median and nine years, respectively (see also Figure A4 in the appendix). As explained in Section 4.4, the focus is on satisfaction as operationalization of health because it is considered a reliable measure of health. Nights in hospital were used here for illustrative reasons. For those interested, the respective indices can be found in Table A6 in the appendix. When comparing the values of the adjusted headcount to the values of the headcount presented in Section 5.1, it must be kept in mind that due to the intermediate approach used, an individual has to be deprived in at least two dimensions in order to be classified as poor. This leads to a smaller poverty index.

All three measures peak in 1991 and have their minimum value in 2000. Nevertheless, there are some differences, which will be described starting with the adjusted headcount, $M_{0}$, for which the measured poverty in 1991 is significantly higher than in the years 1985 to 1989. At 0.05613, the lower limit of the confidence interval for 1991 is above the upper limits of the confidence intervals for 1985 to 1989. A downward trend until the end of the 90s can be seen; and in the years 1998 to 2000, poverty is significantly lower than at the beginning of the 90s. An increase of poverty follows at the beginning of the 2000s; and at the end of the observed period, poverty is significantly higher than at the end of the 90s, back to a level similar to the beginning of the 90 s.

For the adjusted poverty gap, $M_{1}$, the development of poverty is similar, whereby the poverty in 1988 and 1989 is not significantly lower than in 1991 but instead is significantly higher than in 
2000, which is not the case for $M_{0}$. Similar to $M_{0}, M_{1}$ follows an upward trend in the early 2000s. As in the analysis in Section 5.1, the downward trend in the early 90s is weaker for $M_{1}$. In order to better understand the stated differences, the indices are divided into their respective subindices as explained in Section 4.2. The headcount, $H$, average deprivation share, $A$, average poverty gap, $G$, and average severity, $S$, are given in Table 12 and Figure A5.

The headcount develops in the same manner as the adjusted headcount, and thus the dimensional adjustment of multiplying the former with the average deprivation share, $A$, does not have an influence worth mentioning $\left(M_{0}=H A\right)$. Nevertheless, observing the development of $A$ delivers important insights: in 1991, the year with the highest poverty headcount, is also the year in which the average deprivation share is lowest, at an confidence interval between 0.67271 and 0.67936 . This means that in the year with the highest measured poverty according to all three adjusted FGT measures a poor individual is deprived on average in two of the three indicators. This roughly holds for all observed years; whilst for the years 2001 to 2007, A is significantly higher than in 1991, indicating a higher share of the poor being deprived in more than two indicators.

An observation of the development of the average poverty gap, $G$, reveals that it is relatively stable over the years: significant differences between the years are not found. This means that the average depth of poverty of those who are poor did not change over the years. Since $M_{1}$ takes $G$ into account $\left(M_{1}=H A G\right)$, this can explain the slight differences to $M_{0}$ : while the headcount decreases during the 90 s, the average poverty gap stays more or less constant, and thus $M_{1}$ has a weaker downward trend than $M_{0}$.

The differences between $M_{0}$ and $M_{2}$ can be explained in the same way. $M_{2}$ differs insofar as it fails to report hardly any significant poverty differences in the period from 1985 to 1995, which contains the peak in 1991. Only in 1987 is the measure significantly lower than in 1991: the upper limit of the confidence interval is 0.00828 in 1987 and the lower limit of the 1991 confidence interval is 0.00832 . From the mid-90s onwards, $M_{2}$ develops similar to $M_{1}$; however, the upward trend from 2000 on is weaker. Thus, in both time periods for which the poverty headcount and the adjusted poverty headcount increase, $M_{2}$ develops slightly differently. Examining the average severity $S$ can explain why: $S$ is relatively stable over time, with a very weak downward trend. Since $M_{2}$ takes this into account, $M_{2}=H A S$, the upward trends of the poverty headcount are weakened.

Table 11: Adjusted FGT measures for three indicators, ${ }^{1}$ with confidence intervals 


\begin{tabular}{|c|c|c|c|c|c|c|c|c|c|}
\hline & \multicolumn{3}{|c|}{$M_{0}$} & \multicolumn{3}{|c|}{$M_{1}$} & \multicolumn{3}{|c|}{$M_{2}$} \\
\hline & $l c i$ & estimate & $u c i$ & lci & estimate & $u c i$ & $l c i$ & estimate & uci \\
\hline 1985 & .04277 & .04682 & .05095 & .01357 & .01510 & .01665 & .00667 & .00767 & .00867 \\
\hline 1986 & .04273 & .04695 & .05104 & .01330 & .01484 & .01633 & .00647 & .00749 & .00847 \\
\hline 1987 & .04041 & .04480 & .04894 & .01277 & .01434 & .01586 & .00627 & .00729 & .00828 \\
\hline 1988 & .04642 & .05030 & .05453 & .01462 & .01613 & .01769 & .00717 & .00821 & .00926 \\
\hline 1989 & .04592 & .05041 & .05490 & .01484 & .01658 & .01832 & .00741 & .00858 & .00972 \\
\hline 1990 & .04826 & .05321 & .05799 & .01539 & .01717 & .01887 & .00754 & .00868 & .00977 \\
\hline 1991 & .05613 & .05975 & .06374 & .01732 & .01865 & .02010 & .00832 & .00918 & .01012 \\
\hline 1992 & .04966 & .05387 & .05798 & .01565 & .01722 & .01873 & .00764 & .00870 & .00972 \\
\hline 1993 & .04934 & .05320 & .05716 & .01543 & .01694 & .01846 & .00752 & .00854 & .00957 \\
\hline 1994 & .04962 & .05358 & .05767 & .01600 & .01753 & .01912 & .00778 & .00885 & .00996 \\
\hline 1995 & .04697 & .05097 & .05492 & .01511 & .01669 & .01826 & .00719 & .00834 & .00947 \\
\hline 1996 & .04269 & .04682 & .05098 & .01342 & .01493 & .01646 & .00627 & .00723 & .00819 \\
\hline 1997 & .04253 & .04679 & .05112 & .01359 & .01520 & .01687 & .00644 & .00749 & .00860 \\
\hline 1998 & .04034 & .04399 & .04773 & .01260 & .01392 & .01527 & .00587 & .00664 & .00741 \\
\hline 1999 & .03991 & .04391 & .04781 & .01210 & .01348 & .01485 & .00540 & .00623 & .00707 \\
\hline 2000 & .04129 & .04402 & .04683 & .01264 & .01359 & .01457 & .00575 & .00634 & .00694 \\
\hline 2001 & .04562 & .04883 & .05197 & .01409 & .01517 & .01625 & .00641 & .00704 & .00766 \\
\hline 2002 & .04752 & .05107 & .05455 & .01454 & .01577 & .01700 & .00661 & .00734 & .00808 \\
\hline 2003 & .04630 & .04985 & .05342 & .01439 & .01575 & .01709 & .00666 & .00749 & .00832 \\
\hline 2004 & .04896 & .05254 & .05627 & .01492 & .01616 & .01744 & .00678 & .00752 & .00827 \\
\hline 2005 & .05306 & .05731 & .06149 & .01693 & .01845 & .02001 & .00785 & .00873 & .00964 \\
\hline 2006 & .05143 & .05554 & .05957 & .01655 & .01812 & 01965 & .00779 & .00879 & .00975 \\
\hline 2007 & .05038 & .05439 & .05843 & .01513 & .01651 & .01789 & .00683 & .00758 & .00835 \\
\hline
\end{tabular}

Notes: ${ }^{1}$ Health as satisfaction.

Source: Own calculations based on GSOEP data. 
Table 12: Subindices of adjusted FGT measures for three dimensions, ${ }^{1}$ with confidence intervals

\begin{tabular}{|c|c|c|c|c|c|c|c|c|c|c|c|c|}
\hline & & $H$ & & & $A$ & & & $G$ & & & $S$ & \\
\hline & $l c i$ & estimate & uci & $l c i$ & estimate & $u c i$ & lci & estimate & $u c i$ & $l c i$ & estimate & uci \\
\hline 1985 & .06263 & .06856 & .07462 & .67718 & .68280 & .68847 & .30753 & .32261 & .33734 & 14881 & .16376 & .17857 \\
\hline 1986 & .06282 & .06908 & .07513 & .67507 & 67961 & .68428 & .30074 & .31603 & .33125 & .14420 & .15944 & .17459 \\
\hline 1987 & .05872 & .06518 & .07124 & 68110 & .68740 & 69398 & .30492 & .32015 & .33594 & .14735 & .16267 & .17836 \\
\hline 1988 & .06776 & .07348 & .07972 & .67866 & .68450 & .69037 & .30309 & .32068 & .33696 & .14615 & .16318 & .17932 \\
\hline 1989 & .06751 & .07417 & .08084 & .67527 & .67962 & .68404 & .31313 & .32902 & .34459 & .15400 & .17021 & .18581 \\
\hline 1990 & .07095 & .07830 & .08538 & .67532 & .67954 & 68395 & .30825 & .32260 & .33674 & .14845 & .16310 & .17731 \\
\hline 1991 & .08299 & .08838 & .09433 & .67271 & .67604 & .67936 & .30143 & .31211 & .32290 & .14274 & .15357 & .16496 \\
\hline 1992 & .07302 & .07927 & .08537 & .67568 & 67953 & .68346 & .30621 & .31966 & .33260 & .14720 & .16151 & .17527 \\
\hline 1993 & .07216 & .07785 & .08368 & .67858 & .68333 & .68813 & .30455 & .31850 & .33185 & .14636 & .16056 & .17449 \\
\hline 1994 & .07237 & .07816 & .08419 & .67996 & .68547 & .69074 & .31251 & .32719 & .34210 & .14995 & .16526 & .18067 \\
\hline 1995 & .06851 & .07442 & .08025 & .67976 & .68489 & 69012 & .31151 & .32744 & .34340 & .14599 & .16355 & .18110 \\
\hline 1996 & .06231 & .06840 & .07455 & .67884 & .68442 & 68991 & .30414 & .31894 & .33376 & 13967 & .15437 & 16915 \\
\hline 1997 & .06264 & .06896 & .07538 & 67419 & .67851 & .68282 & .30826 & .32477 & .34232 & .14359 & .16007 & .17756 \\
\hline 1998 & .05895 & .06433 & .06981 & .67875 & 68393 & 68915 & .30401 & .31649 & .32894 & 13942 & .15082 & .16236 \\
\hline 1999 & .05833 & .06420 & .06994 & .67855 & 68391 & .68921 & .29270 & .30701 & .32166 & .12828 & .14198 & 15592 \\
\hline 2000 & .06045 & .06444 & .06855 & .67825 & .68311 & .68781 & .29893 & .30874 & .31865 & .13442 & .14401 & .15371 \\
\hline 2001 & .06621 & .07088 & .07546 & .68343 & 68883 & .69422 & .30154 & .31067 & .32011 & .13533 & .14411 & .15313 \\
\hline 2002 & .06894 & .07404 & .07903 & 68397 & .68976 & 69559 & .29876 & .30877 & .31933 & .13416 & .14373 & .15360 \\
\hline 2003 & .06705 & .07220 & .07735 & .68392 & 69048 & .69722 & .30334 & .31591 & .32808 & .13841 & .15032 & 16191 \\
\hline 2004 & .07051 & .07568 & .08105 & 68737 & 69421 & .70139 & .29623 & .30762 & .31880 & .13267 & .14317 & .15343 \\
\hline 2005 & .07629 & .08235 & .08828 & .68856 & .69596 & .70354 & .31158 & .32201 & .33338 & .14268 & .15240 & .16275 \\
\hline 2006 & .07456 & .08044 & .08617 & .68321 & 69049 & 69797 & .31316 & .32625 & .33905 & .14549 & .15821 & .17058 \\
\hline 2007 & .07283 & .07855 & .08428 & .68532 & 69245 & 69967 & .29227 & .30349 & .31475 & .12972 & .13938 & 14919 \\
\hline
\end{tabular}

Notes: ${ }^{1}$ Health as satisfaction.

Source: Own calculations based on GSOEP data.

\subsection{Inequality among the poor}

The subindices directly yield information on the development of depth and severity by calculating the average poverty gap, $G$, and the average severity, $S$, among the poor. Following Alkire and Foster (2008, p. 30), these two specific subindices allow for the calculation of an inequality 
measure, $I E$, which represents the inequality among the poor by subtracting the squared average poverty gap from the average severity:

$$
\text { (7) } I E=S-G^{2} \text {. }
$$

Were the poor totally equal concerning their level of poverty, the average severity would simply be the squared average gap. Hence, a higher $S$ indicates an unequal distribution of the gaps among the poor. The first column of Table 13 and Figure A6 show the development of inequality among the poor. It turns out that inequality significantly decreased from 1985 to 2007: at 0.05349, the lower limit of the confidence interval for 1985 is higher than the upper limit of the confidence interval for 2007, which is at 0.05152. 2007 is the year with the lowest measured inequality; whereas the highest inequality is measured for the beginning of the observed period, with a peak in 1989, where the confidence interval is between 0.0551 and 0.06847 .

The second and the third column of Table 13 contain information on the development of inequality among the poor for West and East Germany. Like the overall inequality, the measures for West and East Germany are given in Figure A6. As mentioned earlier, the GSOEP contains samples for East Germany from 1991 onwards. The interesting result is that the trend in the overall inequality is mainly driven by the development of inequality in West Germany. The inequality measured for West Germany in 2007 is significantly lower than the inequality in 1992 and 1993. In East Germany on the other hand, inequality among the poor does not significantly differ over time.

Table 13: Inequality among poor for three dimensions, ${ }^{1}$ with confidence intervals

\begin{tabular}{ccccccccccc}
\hline \hline & \multicolumn{3}{c}{ IE } & \multicolumn{3}{c}{ IE East } & \multicolumn{3}{c}{ IE West } \\
& lci & estimate & uci & lci & estimate & uci & lci & estimate & uci \\
\hline 1985 & .05349 & .05968 & .06601 & & & & .05349 & .05968 & .06601 \\
1986 & .05293 & .05957 & .06622 & & & & .05293 & .05957 & .06622 \\
1987 & .05347 & .06017 & .06696 & & & & .05347 & .06017 & .06696 \\
1988 & .05363 & .06035 & .06708 & & & & .05363 & .06035 & .06708 \\
1989 & .05511 & .06196 & .06847 & & & & .05511 & .06196 & .06847 \\
1990 & .05249 & .05903 & .06532 & & & & .05249 & .05903 & .06532 \\
1991 & .05107 & .05615 & .06177 & .04765 & .05396 & .06081 & .04996 & .05780 & .06622 \\
1992 & .05271 & .05933 & .06576 & .04338 & .05232 & .06075 & .05389 & .06195 & .06999 \\
1993 & .05292 & .05912 & .06547 & .04018 & .04928 & .05844 & .05422 & .06170 & .06940 \\
1994 & .05178 & .05821 & .06464 & .04178 & .05249 & .06328 & .05189 & .05934 & .06681
\end{tabular}




\begin{tabular}{llllllllll}
1995 & .04849 & .05633 & .06422 & .03446 & .04382 & .05287 & .04959 & .05855 & .06765 \\
1996 & .04634 & .05265 & .05908 & .04015 & .05006 & .06001 & .04587 & .05313 & .06056 \\
1997 & .04765 & .05459 & .06196 & .03841 & .05376 & .06878 & .04736 & .05476 & .06285 \\
1998 & .04593 & .05065 & .05557 & .03711 & .04554 & .05407 & .04606 & .05156 & .05729 \\
1999 & .04202 & .04773 & .05352 & .03374 & .04195 & .05011 & .04244 & .04902 & .05575 \\
2000 & .04443 & .04868 & .05302 & .04144 & .04923 & .05742 & .04348 & .04849 & .05352 \\
2001 & .04364 & .04759 & .05162 & .03747 & .04452 & .05182 & .04376 & .04834 & .05298 \\
2002 & .04417 & .04839 & .05260 & .04001 & .04774 & .05566 & .04358 & .04850 & .05341 \\
2003 & .04579 & .05053 & .05522 & .04139 & .04893 & .05647 & .04536 & .05094 & .05650 \\
2004 & .04421 & .04855 & .05280 & .05015 & .05910 & .06808 & .04031 & .04521 & .05004 \\
2005 & .04476 & .04871 & .05272 & .04370 & .05103 & .05850 & .04345 & .04805 & .05271 \\
2006 & .04664 & .05178 & .05679 & .04716 & .05682 & .06663 & .04450 & .05031 & .05597 \\
2007 & .04318 & .04728 & .05152 & .04176 & .04903 & .05670 & .04168 & .04676 & .05195 \\
\hline \hline
\end{tabular}

Notes: ${ }^{1}$ Health as satisfaction.

Source: Own calculations based on GSOEP data.

Regarding the constellation of the poor and inequality among them, how different occupational groups are represented in 2007 is now analyzed. Therefore, a variable of the GSOEP covering information on the occupational status is used. The poor are divided into three groups regarding their individual average poverty gap in those dimensions in which they are deprived compared to the average poverty gap of the population, $G$. The indication worse means that the average normalized poverty gap of an individual is greater than the upper limit of the confidence interval for the population average poverty gap, $G$, in 2007. Better indicates that the individual average poverty gap is below the population average poverty gap. Same means that the individual poverty gap lies in the confidence interval. The occupational status "pensioner" is assigned to those non-working individuals older than 60 years who receive a retirement pension (or orphan's or widow's pension).The last column gives the number of individuals in the sample for each occupational status. The percentages of the groups are calculated using the individual weights, as in all the analyses so far, and thus are representative for the German population in 2007.

It transpires that at 26.30 percent the unemployed are the group with the largest share of those who are regarded as poor. Almost half of the unemployed poor are in a situation worse than the average poor. Unsurprisingly, the least poor individuals work in those occupations that demand highly qualified workers. In almost all occupational groups of this kind, the poverty rate 
is zero. The group with the second largest number of poor individuals is the group of people working in military and community service. Since only 46 individuals of that group are in the sample, however, this result has to be treated carefully and may be not representative.

An interesting result is that the risk of poverty seems to be much less in the groups of untrained workers and untrained employees than in the group of the unemployed. At 14.36 percent, the share of untrained workers regarded as poor is roughly half as large as the share of poor among the unemployed. Compared to the about 26.30 percent of the unemployed, only 8.96 percent of the untrained employees are poor. For both groups of untrained, the number of poor deprived less than the average outnumber those who are deprived more.

Table 14: Constellation and situation of the poor in 2007. Numbers in columns 1-4 are percentages of subgroup.

\begin{tabular}{|c|c|c|c|c|c|}
\hline \multirow[b]{3}{*}{ Occupational status } & \multicolumn{4}{|c|}{ Situation compared to average } & \multirow[b]{3}{*}{$\mathrm{N}$} \\
\hline & & poor & & not poor & \\
\hline & worse & same & better & & \\
\hline No answer & 2.62 & & 2.79 & 94.59 & 183 \\
\hline Not employed & 4.59 & 1.19 & 6.22 & 87.99 & 1,181 \\
\hline In education & 3.21 & & 2.92 & 93.87 & 468 \\
\hline Unemployed & 12.86 & 1.04 & 12.40 & 73.70 & 995 \\
\hline Pensioner & 5.09 & 0.88 & 6.22 & 87.81 & 4,717 \\
\hline Military, community service & 20.98 & & 1.92 & 77.10 & 46 \\
\hline \multicolumn{6}{|l|}{ Apprentice, trainee industry techno- } \\
\hline $\log y$ & 1.94 & & 0.77 & 97.29 & 184 \\
\hline \multicolumn{6}{|l|}{ Apprentice, trainee trade and com- } \\
\hline merce & 7.38 & 0.36 & 1.21 & 91.05 & 123 \\
\hline Trainee, intern & & & & 100.00 & 41 \\
\hline Untrained worker & 5.83 & 0.45 & 8.08 & 85.64 & 429 \\
\hline Semi-trained worker & 1.43 & 0.58 & 3.35 & 94.64 & 910 \\
\hline Trained worker & 0.66 & 0.27 & 1.41 & 97.66 & 1,142 \\
\hline Foreman, team leader (worker) & & & 0.17 & 99.83 & 186 \\
\hline Foreman (worker) & & & & 100.00 & 83 \\
\hline Self-employed farmer, no coworkers & & & 8.37 & 91.63 & 22 \\
\hline Self-employed farmer, $\leq 9$ coworkers & 17.51 & & & 82.49 & 18 \\
\hline Free-lance professional, no coworkers & & & 2.08 & 97.92 & 197 \\
\hline
\end{tabular}


Free-lance professional, $\leq 9$ cowork-

ers

100.00

Free-lance professional, $>9$ cowork-

ers

100.00 28

Other self-employed, no coworkers

2.06

1.59

96.35 375

Other self-employed, $\leq 9$ coworkers

0.38

2.04

97.58 263

Other self-employed, $>9$ coworkers

4.42

95.58

Help in familiy business

98.43

Foreman (employee)

100.00 56

Untrained employee with simple

tasks

0.61

4.97

91.04

426

Trained employee with simple tasks

0.77

1.56

97.67

Qualified professional

0.79

0.05

0.42

98.74

2,225

Highly qualified professional

100.00

1,405

Managerial

0.58

99.42

198

Low-level civil service

100.00

Middle-level civil service

99.87

High-level civil service

100.00

354

Executive civil service

100.00 250

TOTAL

3.39

0.48

3.98

92.15

17,817

Source: Own calculations based on GSOEP data.

\section{Conclusion}

In this paper, we analyzed multidimensional poverty in Germany using a methodology introduced by Bourguignon and Chakravarty (2003) and Alkire and Foster (2008). The multidimensional measures applied in the analysis have the advantage of delivering information not only on the poverty rate but also on the depth and severity of poverty. All of the indices were tested for the influence of the elasticity of substitution between the poverty indicators. Several robustness tests were performed. The indicators used to measure poverty were income, education and health.

An interesting technical result came to light: the substitutability between achievements on different poverty dimensions has hardly any influence on the results concerning the development of poverty in Germany. One important insight is, that changing levels of the poverty rate do not 
allow for conclusions regarding the situation of the poor. This could be revealed by dividing the indices into several subindices, which give information on the breadth, depth and severity of poverty.

As it is rather more difficult to measure than a purely income based concept of poverty, one could ask whether a multidimensional approach towards poverty is worth the effort. The difficulties arise at different points. Firstly, a thorough theoretical framework has to be designed. The concept of Wagle (2008b), which was briefly introduced, is seen as a good example because it tries to combine several theoretical approaches towards poverty. Secondly, the dimensions of poverty need to be operationalized soundly. In the presented analysis, this happened only at a fundamental level. Thirdly, the identification problem is twofold because one has to define criteria for both within and across dimensions. When using more indicators for each dimension, they can be aggregated into indices for the dimensions, which in turn can be used for further aggregation into the poverty index. Alternatively, the indicators can directly be aggregated into the poverty index. When applying the first alternative, an additional picture of the unidimensional poverty is obtained in each dimension. As for the aggregation problem, further difficulties arise regarding the weighting of the dimensions in the overall measure of poverty created. This happened ad hoc in the presented analysis. One might, for example, use factor or principal component analysis to achieve proper weightings, which especially lends itself in cases of more indicators than the three used here.

One important limitation of the analysis is its cross-sectional design. The measures only represent poverty at a given moment in time without regards to its development in terms of how a certain constellation of achievements leads to certain future outcomes. Poverty dimensions or attributes may be substitutes to each other in the short-run but complements in the long-run (Thorbecke, 2005, p. 20). Different levels of income and education, for example, may lead to the same short-run welfare; in the long-run, however, an individual with relatively more education may improve his or her situation, while an individual with a relative high income stagnates.

Besides its problems, a multidimensional approach as presented here appears to be worth the effort because of delivering insights into poverty valuable for researchers and politicians alike. This is especially true for a more detailed analysis of the structure of poverty: one main gain of the approach presented here, as compared to existing multidimensional work, is the additional information on breadth, depth and severity of poverty. The results show that a decrease in the poverty rate can go hand in hand with a worsening of the situation faced by those who are 
poor. Although the German Federal Government's 3rd Report on Poverty and Wealth takes into account multiple dimensions of poverty for the identification of the poor, it does not report anything about this aspect.

With regards to the results, it turned out that multidimensional measured poverty was lowest at the end of the 1990s. Afterwards, poverty increased again, whereby none of the measures allows for a prediction because the development in the past years did not reveal a major trend. It transpired that the depth of poverty is relatively stable for the observed period, and thus the situation of those who are poor did not change with a changing poverty rate.

Regarding the situation of the poor, further examinations revealed that inequality among the poor did not significantly change for East Germany; whilst it significantly decreased for West Germany. Inequality means that the depth of poverty is unequally distributed among the poor. The last part of the analysis shifted the focus towards the structure of the poor. It turned out that the group at greatest risk of poverty in a multidimensional setting is the unemployed. 


\section{References}

Alkire, Sabina, 2002: "Dimensions of Human Development". In: World Development 30 (2), pp. 181-205.

Alkire, Sabina and James Foster, 2008: "Counting and Multidimensional Poverty Measurement". Oxford Poverty and Human Development Initiative (OPHI), Oxford, Working Paper No. 7.

Anand, Sudhir and Amartya Sen, 1997: “Concepts of Human Development and Poverty: A Multidimensional Perspective". Human Development Papers 1997. UNDP, New York, pp. 1-19.

Bourguignon, Francois and Satya R. Chakravarty, 2003: “The Measurement of Multidimensional Poverty". In: Journal of Economic Inequality 1, pp. 25-49.

Böhnke, Petra and Jan Delhey, 1999: "Poverty in a Multidimensional Perspective: Great Britain and Germany in Comparison“. Wissenschaftszentrum Berlin für Sozialforschung. WZB Discussion Paper FS III 99-413.

Bundesministerium für Arbeit und Soziales (BMAS), 2008: “Lebenslagen in Deutschland. Der 3. Armuts- und Reichtumsbericht der Bundesregierung“. Online (01.12.2009): http://www.bmas.de/portal/26742/property=pdf/dritter armuts_und_reichtumsbericht.pdf.

Coleman, James, 1988: "Social Capital in the Creation of Human Capital". In: American Journal of Sociology 94S, pp. S95-S120.

Deutsch, Joseph and Jacques Silber, 2005: "The Order of Acquisition of Durable Goods and the Multidimensional Measurement of Poverty". Conference Paper for The many Dimensions of Poverty International Conference, UNDP International Poverty Centre, Brasilia, 2005.

Du Toit, Andries, 2007: “Poverty Measurement Blues: Some Reflections on the Space for Understanding 'Chronic' and 'Structural' Poverty in South Africa”. Q-Squared, Centre for International Studies, Toronto, Q-Squared Working Paper No. 33

Fleurbaey, Marc, 2002: “Development, Capabilities, and Freedom”. In: Studies in Comparative International Development 37 (2), pp. 71-77. 
Foster, James, Joel Greer and Erik Thorbecke, 1984: “A Class of Decomposable Poverty Measures". In: Econometrica 52 (3), pp. 761-766.

Glennerster, Howard, 2002: “United States Poverty Studies and Poverty Measurement: The Past Twenty-Five Years". In: Social Service Review 76 (1), pp. 83-107.

Groh-Samberg, Olaf, 2009: “Armut, soziale Ausgrenzung und Klassenstruktur: Zur Integration multidimensionaler und längsschnittlicher Perpektiven". Wiesbaden: VS Verlag für Sozialwissenschaften.

Merz, Joachim and Tim Rathjen, 2009: “Time and Income Poverty. An Interdependent Multidimensional Poverty Approach with German Time Use Diary Data". DIW Berlin. SOEPpapers on Multidisciplinary Panel Data Research 215.

Parsons, Talcott, 1940: “Motivation of Economic Activities". In: Canadian Journal of Economics and Political Science 6 (2), pp. 187-203.

Sen, Amartya, 1976: "Poverty: An Ordinal Approach to Measurement". In: Econometrica 44 (2), pp. 219-231.

Sen, Amartya, 1993: "Capability and Well-being". In: Martha C. Nussbaum and Amartya Sen (eds.): The Quality of Life. Oxford: Oxford University Press, pp. 30-53.

SOEP Group, 2001: “The German Socio-Economic Panel (GSOEP) after more than 15 years Overview". In: Viertljahreshefte zur Wirtschaftsforschung 70 (1), pp. 7-14.

Strengmann-Kuhn, Wolfgang, 2004: "Poverty Measurement with the European Community Household Panel". Paper prepared for the ChangeQual Network Meeting in Paris, first draft.

Thorbecke, Erik, 2005: “Multi-dimensional Poverty: Conceptual and Measurement Issues". Conference Paper for The Many Dimensions of Poverty International Conference, UNDP International Poverty Centre, Brasilia, 2005.

Townsend, Peter, 1974: "Poverty as Relative Deprivation: Resources and Style of Living" In: Dorothy Wedderburn (Ed.): Poverty, Inequality and Class Structure, Cambridge: Cambridge University Press, pp. 15-41.

Waglé, Udaya R., 2008a: “Multidimensional Poverty: An Alternative Measurement Approach for the United States?". In: Social Science Research 37 (2), pp. 559-580. 
Waglé, Udaya R., 2008b: "Multidimensional Poverty Measurement: Concepts and Applications". New York: Springer Science+Business Media, LLC. 


\section{Appendix}

\section{Figures}

Figure A1: Headcount and adjusted headcount, with confidence intervals (income and education)
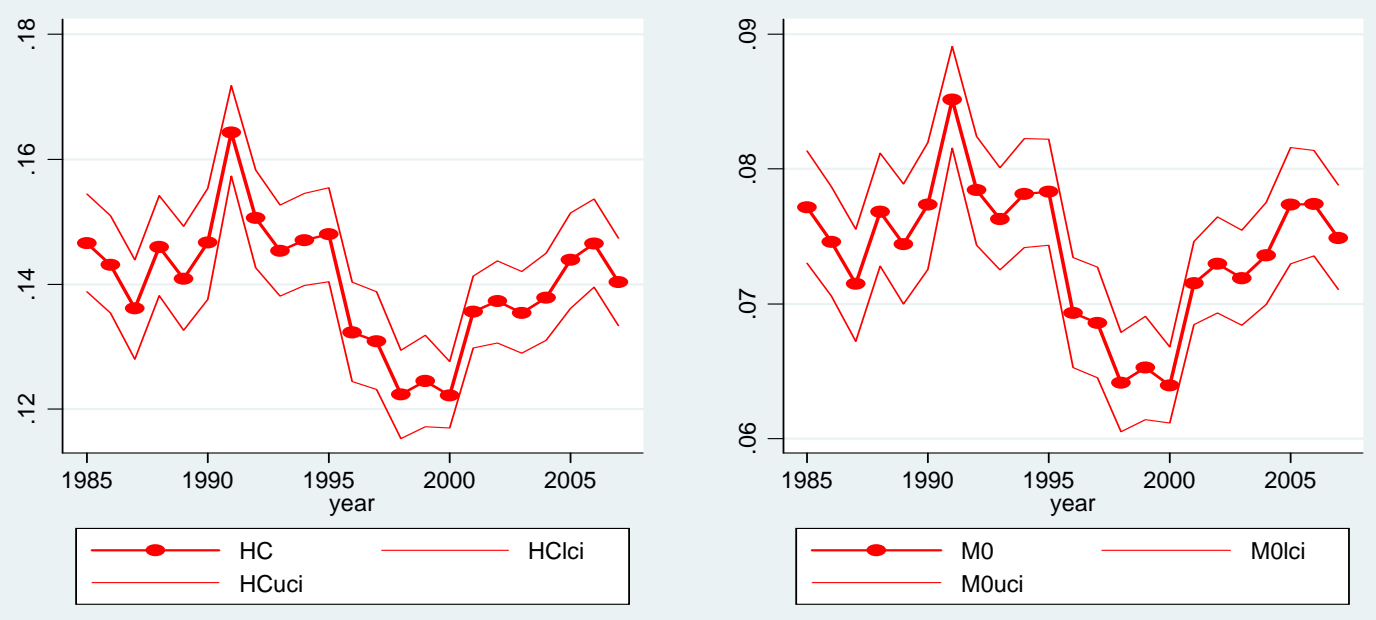

Source: Own calculations based on GSOEP data; 1000 bootstrap repetitions.

Figure A2: Measures using $\alpha=1$, with confidence intervals (income and education)
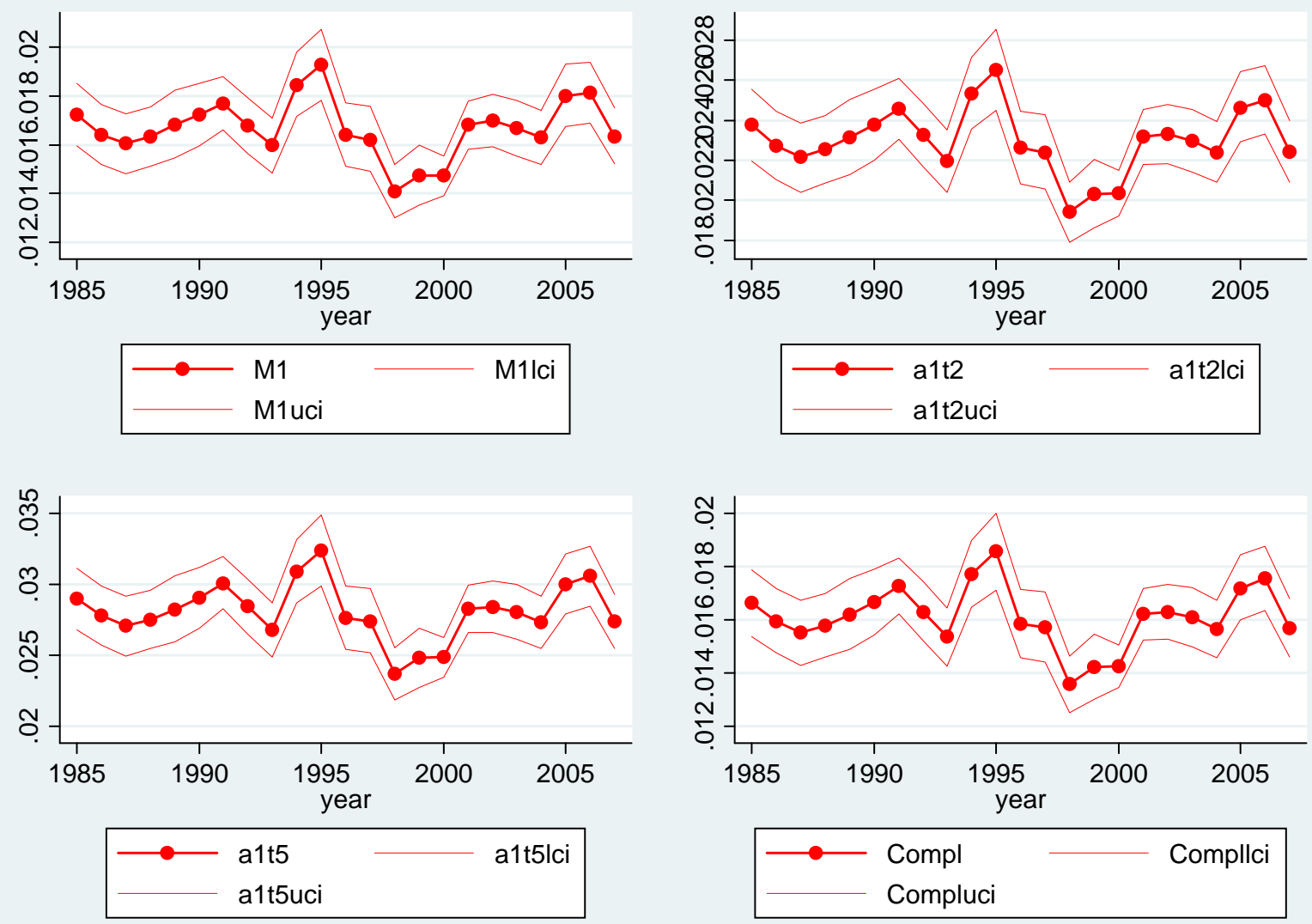

Source: Own calculations based on GSOEP data; 1000 bootstrap repetitions. 
Figure A3: Measures using $\alpha=2$, with confidence intervals (income and education)
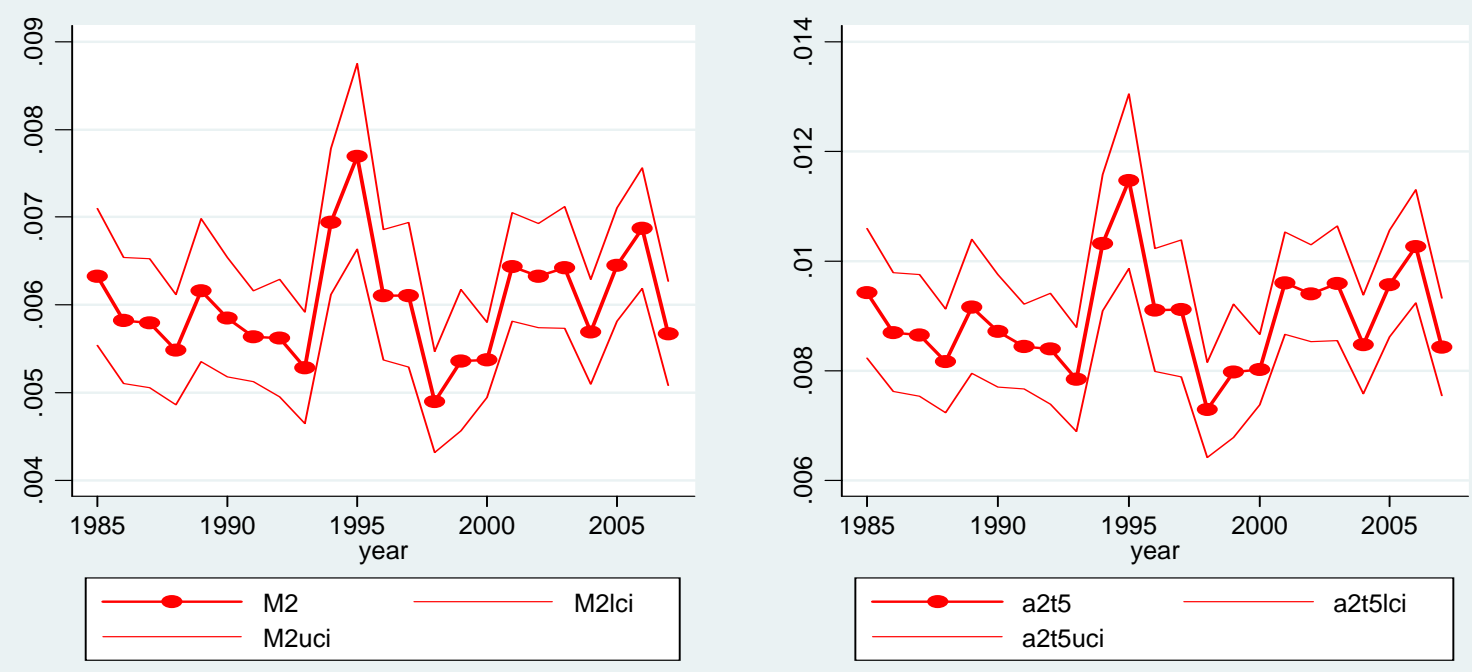

Source: own calculations based on GSOEP data; 1000 bootstrap repetitions

Figure A4: Adjusted FGT measures for three indicators, ${ }^{1}$ with confidence intervals
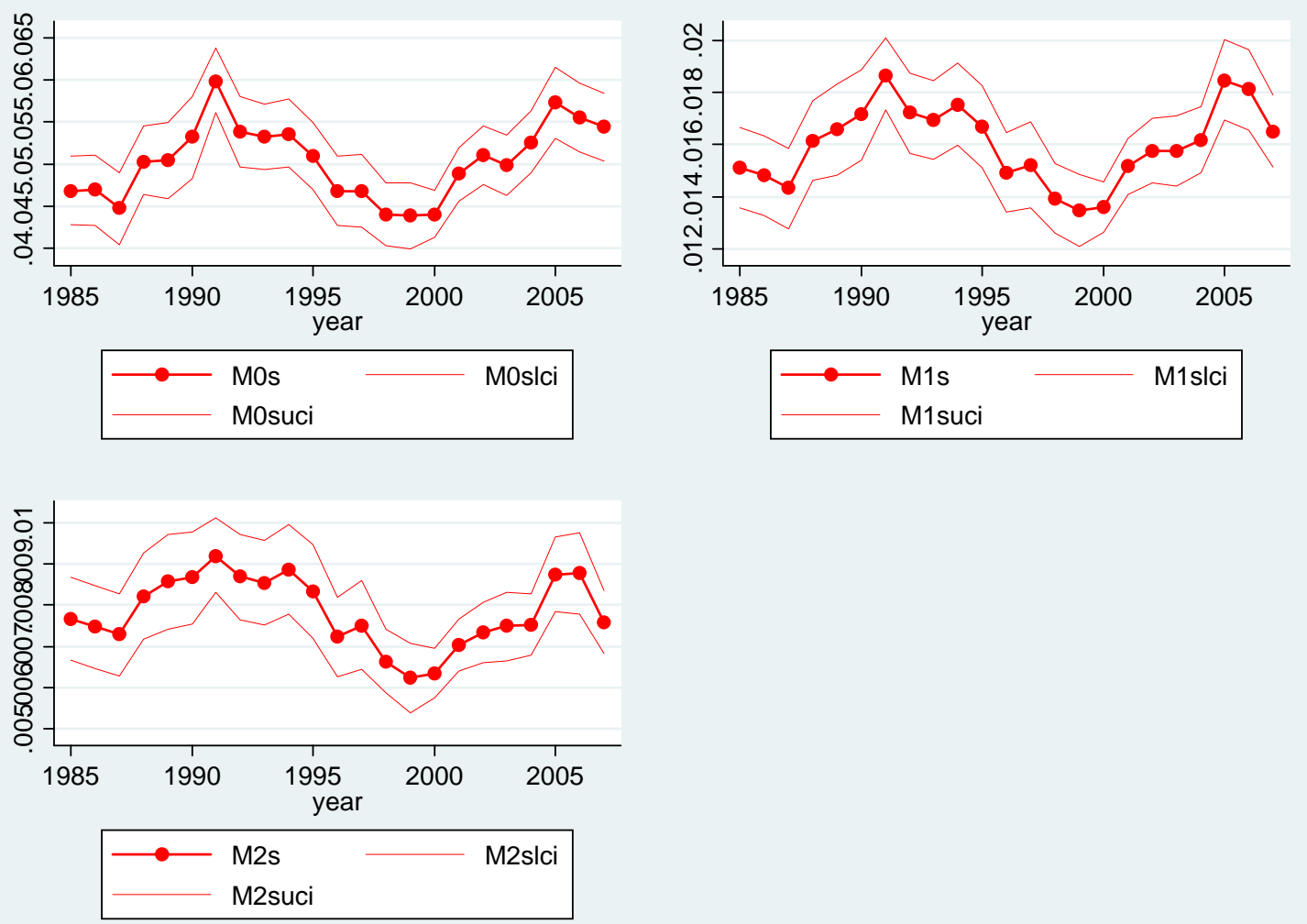

Notes: ${ }^{1}$ Health as satisfaction.

Source: Own calculations based on GSOEP data; 1000 bootstrap repetitions 
Figure A5: Subindices of adjusted FGT measures for three indicators ${ }^{1}$, with confidence intervals
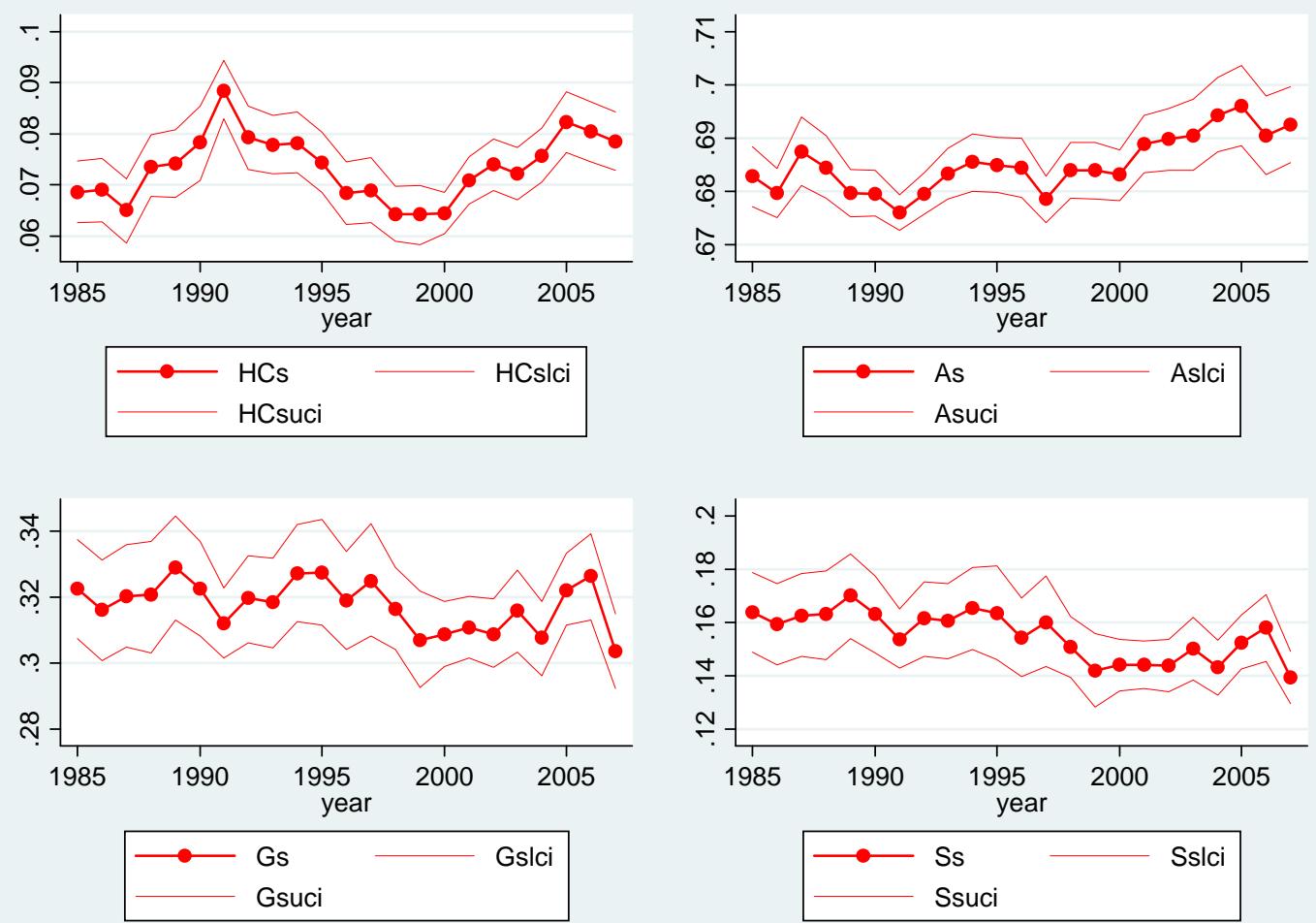

Notes: ${ }^{1}$ Health as satisfaction.

Source: Own calculations based on GSOEP data; 1000 bootstrap repetitions

Figure A6: Inequality measure for three indicators, with confidence intervals; Germany, East, West 

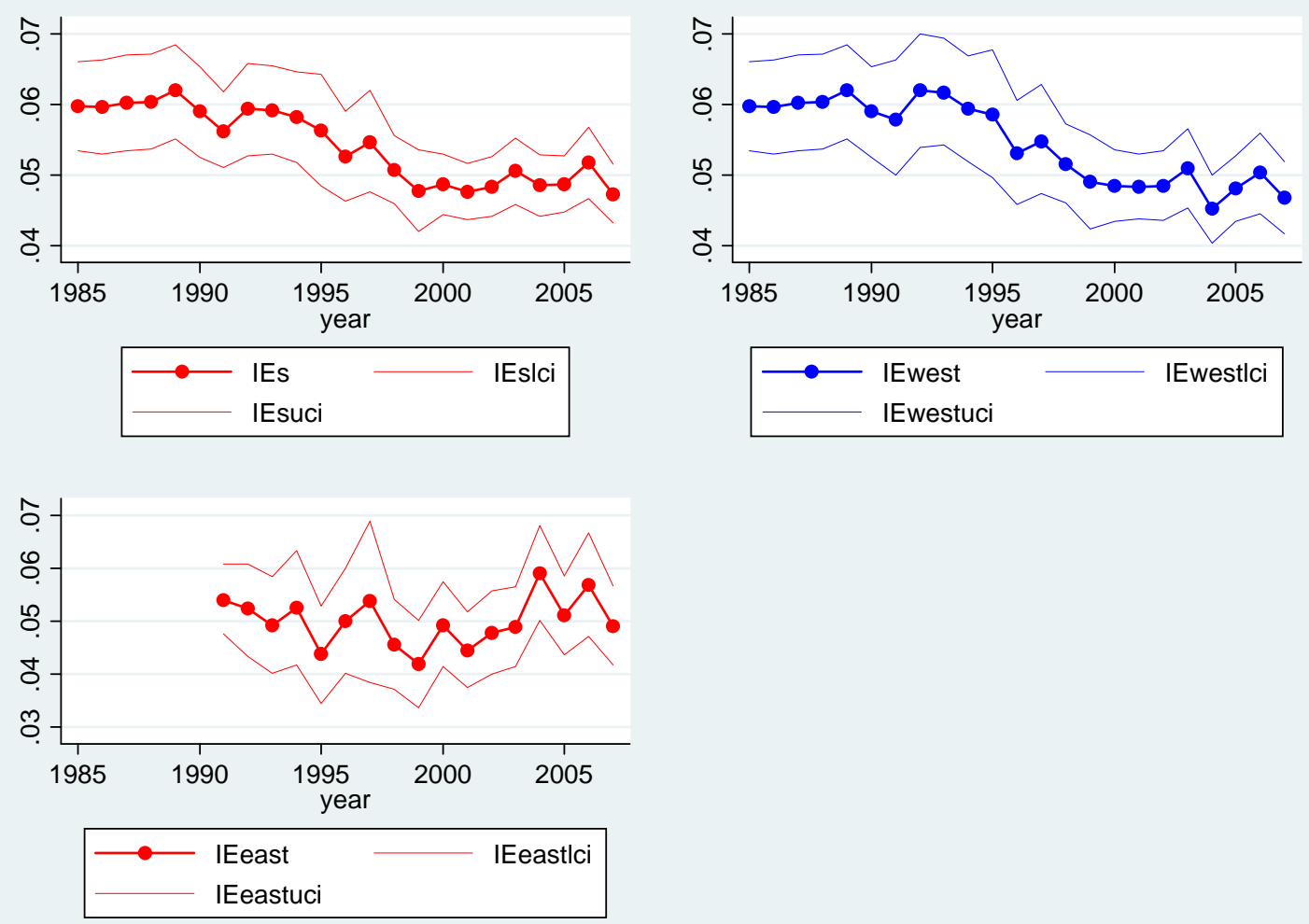

Notes: ${ }^{1}$ Health as satisfaction.

Source: Own calculations based on GSOEP data; 1000 bootstrap repetitions. 


\section{Tables}

Table A1: $H$ and $M_{0}$ with confidence intervals (income-poverty line at 80 percent of median)

\begin{tabular}{ccccccc}
\hline \hline & \multicolumn{3}{c}{$H$} & & \multicolumn{3}{c}{$M_{0}$} \\
& lci & estimate & $u c i$ & lci & estimate & $u c i$ \\
\hline 1985 & .29999 & .30871 & .31721 & .15766 & .16229 & .16681 \\
1986 & .29260 & .30061 & .30920 & .15332 & .15764 & .16222 \\
1987 & .28424 & .29379 & .30257 & .14949 & .15450 & .15912 \\
1988 & .28992 & .29916 & .30798 & .15269 & .15765 & .16237 \\
1989 & .29410 & .30166 & .31105 & .15566 & .15978 & .16485 \\
1990 & .28476 & .29513 & .30516 & .15116 & .15676 & .16215 \\
1991 & .30819 & .31627 & .32457 & .16022 & .16450 & .16888 \\
1992 & .31013 & .31835 & .32641 & .16150 & .16595 & .17024 \\
1993 & .29580 & .30429 & .31265 & .15579 & .16029 & .16476 \\
1994 & .29657 & .30499 & .31357 & .15671 & .16132 & .16599 \\
1995 & .28744 & .29647 & .30502 & .15128 & .15608 & .16061 \\
1996 & .27237 & .28237 & .29217 & .14272 & .14792 & .15305 \\
1997 & .27273 & .28099 & .29017 & .14273 & .14705 & .15194 \\
1998 & .26470 & .27546 & .28491 & .13870 & .14460 & .14972 \\
1999 & .26899 & .27797 & .28700 & .14112 & .14595 & .15080 \\
2000 & .27067 & .27767 & .28394 & .14088 & .14455 & .14785 \\
2001 & .28550 & .29189 & .29835 & .14890 & .15225 & .15568 \\
2002 & .28629 & .29321 & .30031 & .14947 & .15319 & .15703 \\
2003 & .28382 & .29211 & .29988 & .14814 & .15255 & .15672 \\
2004 & .28953 & .29668 & .30435 & .15144 & .15531 & .15946 \\
2005 & .29726 & .30393 & .31137 & .15586 & .15966 & .16388 \\
2006 & .29112 & .29899 & .30646 & .15169 & .15609 & .16029 \\
2007 & .29856 & .30620 & .31388 & .15598 & .16024 & .16454 \\
\hline \hline
\end{tabular}

Source: Own calculations based on GSOEP data. 
Table A2: Measures using $\alpha=1$, with confidence intervals (income-pl at 80 percent of median)

\begin{tabular}{|c|c|c|c|c|c|c|c|c|c|c|c|c|}
\hline & & $M_{1}=P_{1}^{1}$ & & & $P_{1}^{2}$ & & & $P_{1}^{5}$ & & & Compl & \\
\hline & $l c i$ & estimate & uci & $l c i$ & estimate & $u c i$ & $l c i$ & estimate & uci & $l c i$ & estimate & $u c i$ \\
\hline 1985 & .03647 & .03817 & .03984 & .05025 & .05259 & .05489 & .06133 & .06419 & .06700 & .07034 & .07362 & .07685 \\
\hline 1986 & .03502 & .03671 & .03838 & .04838 & .05071 & .05301 & .05909 & .06194 & .06475 & .06777 & .07104 & .07427 \\
\hline 1987 & .03435 & .03603 & .03765 & .04733 & .04965 & .05188 & .05774 & .06059 & .06332 & .06621 & .06947 & .07261 \\
\hline 1988 & .03562 & .03730 & .03897 & .04903 & .05135 & .05366 & .05979 & .06264 & .06546 & .06854 & .07181 & 07506 \\
\hline 1989 & .03553 & .03724 & .03906 & .04881 & .05114 & .05362 & .05952 & .06236 & .06539 & .06824 & .07151 & .07499 \\
\hline 1990 & .03549 & .03731 & .03912 & .04876 & .05125 & .05375 & .05944 & .06249 & .06554 & .06814 & .07164 & .07514 \\
\hline 1991 & .03892 & .04042 & .04196 & .05405 & .05612 & .05825 & .06614 & .06868 & .07129 & .07589 & .07880 & .08180 \\
\hline 1992 & .03761 & .03916 & .04071 & .05208 & .05423 & .05637 & .06365 & .06629 & .06892 & .07302 & .07604 & .07906 \\
\hline 1993 & .03542 & .03700 & .03854 & .04882 & .05101 & .05313 & .05960 & .06228 & .06489 & .06837 & .07145 & .07443 \\
\hline 1994 & .03761 & .03923 & .04093 & .05169 & .05389 & .05621 & .06306 & .06574 & .06857 & .07232 & .07539 & . 07864 \\
\hline 1995 & .03700 & .03880 & .04057 & .05096 & .05345 & .05591 & .06222 & .06527 & .06828 & .07137 & .07488 & .07833 \\
\hline 1996 & .03329 & .03502 & .03676 & .04599 & .04840 & .05081 & .05622 & .05917 & .06214 & .06450 & .06789 & .07130 \\
\hline 1997 & .03318 & .03482 & .03660 & .04590 & .04817 & .05064 & .05612 & .05891 & .06193 & .06440 & .06760 & .07107 \\
\hline 1998 & .03038 & .03197 & .03349 & .04195 & .04415 & .04625 & .05127 & .05396 & .05653 & .05883 & .06192 & .06487 \\
\hline 1999 & .03180 & .03343 & .03508 & .04390 & .04615 & .04844 & .05362 & .05638 & .05919 & .06149 & .06467 & .06789 \\
\hline 2000 & .03320 & .03438 & .03552 & .04604 & .04768 & .04925 & .05632 & .05833 & .06026 & .06462 & .06693 & .06915 \\
\hline 2001 & .03628 & .03755 & .03885 & .05025 & .05202 & .05381 & .06147 & .06364 & .06584 & .07054 & .07304 & .07556 \\
\hline 2002 & .03680 & .03820 & .03964 & .05089 & .05281 & .05479 & .06223 & .06458 & .06701 & .07141 & .07411 & .07689 \\
\hline 2003 & .03634 & .03786 & .03935 & .05029 & .05239 & .05443 & .06148 & .06405 & .06655 & .07054 & .07349 & .07636 \\
\hline 2004 & .03621 & .03768 & .03920 & .05003 & .05205 & .05415 & .06111 & .06360 & .06617 & .07011 & .07297 & .07592 \\
\hline 2005 & .03857 & .04018 & .04188 & .05322 & .05541 & .05773 & .06500 & .06768 & .07052 & .07458 & .07766 & .08091 \\
\hline 2006 & .03785 & .03949 & .04110 & .05249 & .05474 & .05694 & .06423 & .06699 & .06969 & .07372 & .07688 & .07998 \\
\hline 2007 & .03712 & .03862 & .04016 & .05139 & .05343 & .05552 & .06286 & .06535 & .06791 & .07214 & .07500 & .07794 \\
\hline
\end{tabular}

Source: Own calculations based on GSOEP data. 
Table A3: Measures using $\alpha=2$, with confidence intervals (income-pl at 80 percent of median)

\begin{tabular}{|c|c|c|c|c|c|c|}
\hline & & $M_{2}$ & & & $P_{2}^{5}$ & \\
\hline & $l c i$ & estimate & $u c i$ & $l c i$ & estimate & $u c i$ \\
\hline 1985 & .01281 & .01383 & .01484 & .01907 & .02060 & .02212 \\
\hline 1986 & .01222 & .01318 & .01415 & .01823 & .01968 & .02113 \\
\hline 1987 & .01197 & .01295 & .01391 & 01781 & .01929 & .02074 \\
\hline 1988 & .01223 & .01315 & .01408 & .01818 & .01956 & .02096 \\
\hline 1989 & .01241 & .01345 & .01453 & .01844 & .01999 & .02161 \\
\hline 1990 & .01245 & .01344 & .01443 & .01851 & .01998 & .02147 \\
\hline 1991 & .01363 & .01443 & .01525 & .02040 & .02161 & .02284 \\
\hline 1992 & .01292 & .01381 & .01470 & .01929 & .02062 & .02197 \\
\hline 1993 & .01200 & .01289 & .01376 & .01786 & .01919 & .02050 \\
\hline 1994 & .01374 & .01476 & .01582 & .02043 & .02195 & .02354 \\
\hline 1995 & .01407 & .01531 & .01654 & .02097 & .02283 & .02468 \\
\hline 1996 & .01217 & .01318 & .01420 & .01817 & .01970 & .02123 \\
\hline 1997 & .01215 & .01319 & .01427 & .01816 & .01972 & .02136 \\
\hline 1998 & .01066 & .01150 & .01233 & .01590 & .01717 & .01841 \\
\hline 1999 & .01127 & .01226 & .01328 & .01680 & .01830 & .01984 \\
\hline 2000 & .01217 & .01280 & .01343 & .01821 & .01916 & .02011 \\
\hline 2001 & .01376 & .01455 & .01535 & .02058 & .02178 & .02298 \\
\hline 2002 & .01389 & .01471 & .01556 & .02075 & .02198 & .02325 \\
\hline 2003 & .01374 & .01465 & .01555 & .02052 & .02189 & .02325 \\
\hline 2004 & .01323 & .01407 & .01493 & .01974 & .02100 & .02229 \\
\hline 2005 & .01447 & .01540 & .01637 & .02156 & .02296 & .02442 \\
\hline 2006 & .01460 & .01556 & .01652 & .02186 & .02330 & .02474 \\
\hline 2007 & .01347 & .01432 & .01518 & .02013 & .02140 & .02269 \\
\hline
\end{tabular}

Notes: ${ }^{1} 1000$ bootstrap repetitions.

Source: Own calculations based on GSOEP data. 
Table A4: $M_{0}$ and $\alpha=1$ measures, with confidence intervals (unequal weights of income and education)

\begin{tabular}{|c|c|c|c|c|c|c|c|c|c|c|c|c|}
\hline & & $M_{0}$ & & & $M_{1}$ & & & $P_{1}^{2}$ & & & $\overline{P_{1}^{5}}$ & \\
\hline & $l c i$ & estimate & uci & $l c i$ & estimate & uci & $l c i$ & estimate & $u c i$ & $l c i$ & estimate & $u c i$ \\
\hline 1985 & .08554 & .09074 & .09603 & .01868 & .02040 & .02211 & .02352 & .02557 & .02761 & .02745 & .02977 & .03205 \\
\hline 1986 & .08329 & .08838 & .09357 & .01788 & .01952 & .02117 & .02257 & .02453 & .02650 & .02636 & .02857 & .03079 \\
\hline 1987 & .07872 & .08425 & .08947 & .01739 & .01907 & .02072 & .02190 & .02390 & .02587 & .02556 & .02781 & .03002 \\
\hline 1988 & .08666 & .09177 & .09735 & .01787 & .01949 & .02112 & .02244 & .02437 & .02633 & .02614 & .02831 & .03051 \\
\hline 1989 & .08137 & .08687 & .09249 & .01805 & .01985 & .02171 & .02274 & .02487 & .02708 & .02657 & .02897 & .03145 \\
\hline 1990 & .08451 & .09067 & .09655 & .01864 & .02034 & .02206 & .02353 & .02554 & .02759 & .02752 & .02978 & .03208 \\
\hline 1991 & .09990 & .10457 & 10969 & .02018 & .02162 & .02309 & .02520 & .02692 & .02867 & .02918 & .03111 & .03308 \\
\hline 1992 & .08958 & .09493 & .10009 & .01882 & .02032 & .02184 & .02353 & .02534 & .02716 & .02730 & .02933 & .03138 \\
\hline 1993 & .08643 & .09115 & .09601 & .01754 & .01905 & .02054 & .02197 & .02377 & .02555 & .02555 & .02758 & .02958 \\
\hline 1994 & .08761 & .09247 & .09751 & .02056 & .02228 & .02406 & .02556 & .02759 & .02971 & .02959 & .03187 & .03424 \\
\hline 1995 & .08757 & .09263 & .09754 & .02147 & .02346 & .02544 & .02667 & .02904 & .03140 & 03083 & .03348 & .03613 \\
\hline 1996 & .07734 & .08251 & .08773 & .01828 & .02002 & .02177 & .02272 & .02481 & .02690 & .02627 & .02861 & .03097 \\
\hline 1997 & .07724 & .08240 & .08766 & .01820 & .01996 & .02180 & .02258 & .02468 & .02688 & .02604 & .02839 & .03086 \\
\hline 1998 & .07285 & .07754 & .08226 & .01584 & .01731 & .01875 & .01963 & .02137 & .02309 & .02262 & .02457 & .02650 \\
\hline 1999 & .07451 & .07937 & .08423 & .01663 & .01828 & 01997 & .02052 & .02248 & .02451 & .02357 & .02577 & .02804 \\
\hline 2000 & .07725 & .08088 & .08462 & .01785 & .01896 & .02006 & .02170 & .02302 & .02433 & .02462 & .02609 & .02756 \\
\hline 2001 & .08711 & .09108 & .09506 & .02047 & .02180 & .02315 & .02474 & .02633 & .02793 & .02796 & .02974 & .03153 \\
\hline 2002 & .08842 & .09310 & .09757 & .02063 & .02206 & .02353 & .02484 & .02653 & .02828 & .02802 & .02991 & .03186 \\
\hline 2003 & .08731 & .09175 & .09633 & .02015 & .02169 & .02324 & .02431 & .02614 & .02798 & .02745 & .02950 & .03155 \\
\hline 2004 & .08884 & .09354 & .09853 & .01957 & .02104 & .02255 & .02363 & .02539 & .02718 & .02670 & .02866 & .03066 \\
\hline 2005 & .09291 & .09845 & .10373 & .02172 & .02340 & .02514 & .02608 & .02806 & .03012 & .02936 & .03157 & .03387 \\
\hline 2006 & .09420 & .09900 & .10396 & .02198 & .02366 & .02534 & .02653 & .02853 & .03053 & 02996 & .03219 & .03442 \\
\hline 2007 & .09088 & .09571 & .10065 & .01974 & .02124 & .02278 & .02377 & .02554 & .02736 & .02681 & .02879 & .03082 \\
\hline
\end{tabular}


Table A5: Measures using $\alpha=2$, with confidence intervals (unequal weights of income and education)

\begin{tabular}{|c|c|c|c|c|c|c|}
\hline & & $M_{2}$ & & & $P_{2}^{5}$ & \\
\hline & $l c i$ & estimate & $u c i$ & $l c i$ & estimate & $u c i$ \\
\hline 1985 & .00693 & .00802 & .00911 & .00895 & .01030 & .01164 \\
\hline 1986 & .00639 & .00738 & .00839 & .00828 & .00951 & .01075 \\
\hline 1987 & .00634 & .00736 & .00837 & .00819 & .00946 & 01071 \\
\hline 1988 & .00607 & .00693 & .00781 & .00785 & .00892 & . 01001 \\
\hline 1989 & .00669 & .00780 & .00894 & .00864 & 01001 & .01142 \\
\hline 1990 & .00642 & .00736 & .00831 & .00833 & .00949 & 01067 \\
\hline 1991 & .00649 & .00720 & .00792 & .00837 & .00925 & .01014 \\
\hline 1992 & .00625 & .00717 & .00810 & .00805 & .00920 & .01036 \\
\hline 1993 & .00579 & .00667 & .00754 & .00748 & .00856 & .00965 \\
\hline 1994 & .00779 & .00893 & .01010 & .00996 & .01137 & .01281 \\
\hline 1995 & .00852 & .01000 & .01146 & .01086 & .01269 & .01450 \\
\hline 1996 & .00688 & .00791 & .00895 & .00879 & .01006 & .01135 \\
\hline 1997 & .00682 & .00796 & .00912 & .00870 & .01010 & .01154 \\
\hline 1998 & .00553 & .00633 & .00713 & .00705 & .00805 & .00903 \\
\hline 1999 & .00588 & .00699 & .00813 & .00748 & .00885 & .01026 \\
\hline 2000 & .00657 & .00716 & .00776 & .00826 & .00898 & .00972 \\
\hline 2001 & .00778 & .00864 & .00950 & .00972 & .01079 & .01186 \\
\hline 2002 & .00768 & .00849 & .00932 & .00958 & .01057 & .01160 \\
\hline 2003 & .00768 & .00864 & .00961 & .00959 & .01078 & .01198 \\
\hline 2004 & .00677 & .00759 & .00842 & .00848 & .00949 & .01052 \\
\hline 2005 & .00776 & .00864 & .00955 & .00967 & .01076 & .01188 \\
\hline 2006 & .00831 & .00925 & .01021 & .01038 & .01156 & .01274 \\
\hline 2007 & .00678 & .00759 & .00842 & .00846 & .00947 & .01049 \\
\hline
\end{tabular}

Source: Own calculations based on GSOEP data. 
Table A6: Adjusted FGT measures for three dimensions, ${ }^{1}$ with confidence intervals

\begin{tabular}{|c|c|c|c|c|c|c|c|c|c|}
\hline & \multicolumn{3}{|c|}{$M_{0}$} & \multicolumn{3}{|c|}{$\overline{\bar{M} M_{1}}$} & \multicolumn{3}{|c|}{$\bar{M} M_{2}$} \\
\hline & $l c i$ & estimate & uci & $l c i$ & estimate & $u c i$ & $l c i$ & estimate & $u c i$ \\
\hline 1985 & .01622 & .01867 & .02114 & .00288 & .00342 & .00396 & .00094 & .00124 & .00154 \\
\hline 1986 & .01510 & .01765 & .02014 & .00282 & .00341 & .00399 & .00099 & .00131 & .00162 \\
\hline 1987 & .01462 & 01715 & .01968 & .00252 & .00303 & .00354 & .00074 & .00099 & .00124 \\
\hline 1988 & .01626 & .01894 & .02167 & .00299 & .00359 & .00421 & .00087 & .00119 & .00152 \\
\hline 1989 & n.o. ${ }^{2}$ & n.o. & n.o. & n.o. & n.o. & n.o. & n.o. & n.o. & n.o. \\
\hline 1990 & .01813 & .02104 & .02411 & .00297 & .00359 & .00421 & .00085 & .00116 & .00148 \\
\hline 1991 & .01696 & .01937 & .02193 & .00262 & .00311 & .00361 & .00077 & .00100 & .00123 \\
\hline 1992 & n.o. & n.o. & n.o. & n.o. & n.o. & n.o. & n.o. & n.o. & n.o. \\
\hline 1993 & .01813 & .02073 & .02340 & .00284 & .00337 & .00390 & .00076 & .00099 & .00121 \\
\hline 1994 & 01773 & .02027 & .02281 & .00332 & .00400 & .00468 & .00111 & .00154 & .00197 \\
\hline 1995 & .01794 & .02049 & .02303 & .00351 & .00413 & .00475 & .00120 & .00153 & .00186 \\
\hline 1996 & .01553 & .01794 & .02035 & .00267 & .00316 & .00367 & .00086 & .00110 & .00134 \\
\hline 1997 & .01374 & .01596 & .01830 & .00254 & .00307 & .00362 & .00083 & .00111 & .00140 \\
\hline 1998 & .01359 & .01583 & .01806 & .00209 & .00252 & .00294 & .00060 & .00079 & .00098 \\
\hline 1999 & .01425 & .01684 & .01942 & .00222 & .00272 & .00324 & .00061 & .00086 & .00112 \\
\hline 2000 & .01375 & .01535 & .01699 & .00226 & .00259 & .00293 & .00067 & .00082 & .00098 \\
\hline 2001 & .01503 & .01695 & .01887 & .00250 & .00293 & .00335 & .00075 & .00097 & .00119 \\
\hline 2002 & .01808 & .02037 & .02269 & .00321 & .00366 & .00414 & .00106 & .00128 & .00150 \\
\hline 2003 & .01595 & .01820 & .02043 & .00267 & .00316 & .00365 & .00087 & .00112 & .00137 \\
\hline 2004 & .01672 & .01888 & .02110 & .00267 & .00311 & .00356 & .00072 & .00092 & .00113 \\
\hline 2005 & .01832 & .02099 & .02369 & .00306 & .00364 & .00423 & .00090 & .00116 & .00142 \\
\hline 2006 & .01598 & .01840 & .02082 & .00273 & .00325 & .00378 & .00088 & .00115 & .00142 \\
\hline 2007 & .01678 & .01900 & .02141 & .00261 & .00310 & .00361 & .00074 & .00097 & .00119 \\
\hline
\end{tabular}

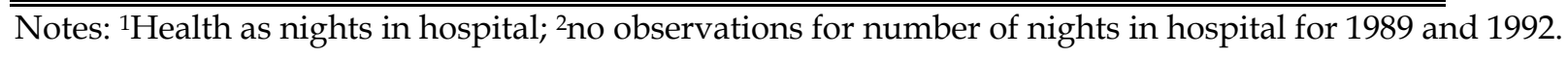

Source: Own calculations based on GSOEP data; 1000 bootstrap repetitions. 